Submitted to Meta-Psychology. Participate in open peer review by commenting through hypothes.is directly on this preprint. The full editorial process of all articles under review at Meta-Psychology can be found following this link:

https://tinyurl.com/mp-submissions

You will find this preprint by searching for the first authors name.

\title{
Defaults versus framing: Revisiting Default Effect and Framing Effect with replications and extensions of Johnson and Goldstein (2003) and Johnson, Bellman, and Lohse (2002)
}

\author{
* Subramanya Prasad Chandrashekar \\ Prasad.chandrashekar@gmail.com \\ ORCID: 0000-0002-8599-9241
}
*Nadia Adelina, *Shiyuan Zeng, *Yan Ying Esther Chiu, *Yat Sum Grace Leung Department of Psychology, University of Hong Kong, Hong Kong SAR
u3544512@connect.hku.hk / nadia.adelina19@gmail.com;
shiyuanv@hku.hk/VanessaZeng@163.com;
estherchiu.yy@hku.hk / estherchiu.yy@gmail.com;
u3546662@connect.hku.hk/gracelys99@gmail.com

\author{
Paul Henne \\ Department of Philosophy, \\ Neuroscience Program, \\ Lake Forest College \\ phenne@lakeforest.edu \\ ORCID: 0000-0002-3526-2911 \\ Boley Cheng \\ University of Hong Kong \\ boleystudies@gmail.com \\ ${ }^{\wedge}$ Gilad Feldman \\ Department of Psychology, University of Hong Kong, Hong Kong SAR \\ gfeldman@hku.hk / giladfel@gmail.com \\ ORCID: 0000-0003-2812-6599
}

*Contributed equally

${ }^{\wedge}$ Corresponding author

Word: abstract - 249, manuscript - 6802 (excluding figures, tables, and references) 


\section{Acknowledgements}

Nadia Adelina, Shiyuan Zeng, Yan Ying Esther Chiu, and Grace Yat-Sum Leung analyzed the original articles, wrote the pre-registrations, designed the replications and the extensions, and conducted an initial analysis of the results and write-up of the first draft. Boley Cheng guided and assisted the replication effort. Subramanya Prasad Chandrashekar and Paul Henne verified and extended analyses, integrated the studies, and wrote the final manuscript for submission. Gilad Feldman led the replication efforts, supervised each step, conducted the pre-registrations, ran data collections, provided feedback throughout, and edited the final manuscript for submission.

We would like to thank Ignazio Ziano and Jieying Chen for their feedback reviewing initial drafts of this project. 


\begin{abstract}
People tend to stick with a default option instead of switching to another option. For instance, Johnson and Goldstein (2003) found a default effect in an organ donation scenario: if organ donation is the default option, people are more inclined to consent to it. Johnson et al. (2002) found a similar default effect in a health-survey scenarios: if receiving more information about your health is the default, people are more inclined to consent to it. Much of the highly cited, impactful work on these default effects, however, has not been replicated in well-powered samples. In two well-powered samples $(N=1920)$, we conducted a close replication of the default effect in Johnson and Goldstein (2003) and in Johnson, Bellman, and Lohse (2002). We successfully replicated Johnson and Goldstein (2003). In an extension of the original findings, we also show that default effects are unaffected by the permanence of these selections. We, however, failed to replicate the findings of Johnson, Bellman, and Lohse's (2002) study; we did not find evidence for a default effect. We did, however, find a framing effect: participants who read a positively-framed scenario consented to receive health-related information at a higher rate than participants who read a negatively framed scenario. We also conducted a conceptual replication of Johnson et al. (2002) that was based on an organ-donation scenario, but this attempt failed to find a default effect. Our results suggest that default effects depend on framing and context. Materials, data, and code are available on: https://osf.io/8wd2b/.
\end{abstract}

Keywords: action framing effect; default effect; organ donation; nudge; replication; choice; judgment and decision making 
Defaults versus framing: Revisiting Default Effect and Framing Effect with a replication and extension of Johnson and Goldstein (2003) and Johnson, Bellman, and Lohse (2002)

Suppose that people receive a health survey after a doctor's appointment in order to see if they would like to receive health updates from their doctors. If the option to participate is preselected, people would probably not change their response-instead sticking with the default option and participating in the service. This is an example of the default effect: given a default option, people stick with it rather than changing (Johnson \& Goldstein, 2003; Johnson et al., 1993).

The framing of the options may also affect people's choices. In this example, people would be more inclined to select an option if it is framed positively, as in answering "Yes" to "I will participate," as opposed to negatively, as in selecting "No" to "I will not participate." This is an example of a framing effect: people consent to participate at a higher rate when a choice is positively framed than when it is negatively framed (Johnson \& Goldstein, 2003).

Default effects and framing effects have been very influential across many academic disciplines and in public policy (Araña \& León, 2013; Evans et al., 2011; Johnson \& Goldstein, 2003; Mintz \& Redd, 2003; Tversky \& Kahneman, 1981). The use of default effects is a wellknown effective example of leveraging behavioral insights to influence people or to nudge them toward specific socially desirable choices. Governments and public policy organizations worldwide have set-up Nudge Units that implemented interventions using default effects to encourage desired behavior encouraging organ donations and pension savings (Halpern, 2015).

There is, however, some evidence for an overestimation of the size of nudge effects. For instance, DellaVigna and Linos (2020) recently found that there were larger effect sizes for 
nudge interventions reported in published literature than those reported by Nudge Units in the United States. This finding suggests that selective reporting may lead to inflated meta-analytic effect sizes (Kvarven et al., 2020). Moreover, in some cases, nudge effects did not replicate with larger samples (Bohner \& Schlüter, 2014; Kettle et al., 2017; Kristal et al., 2020).

Given these recent findings, there is reason to investigate default effects and framing effects. Despite a substantial number of experimental studies on default effects, for instance, very few of these employed preregistered analysis plans using well-powered samples (Szaszi et al., 2018). Together, these may lead to misplaced optimism about easy-to-implement nudging interventions, while much more complex solutions involving structural reforms have been ignored (Schmidt \& Engelen, 2020). As such, researchers have called for more preregistered replications using well-powered samples (Ferguson \& Heene, 2012; Franco et al., 2014).

In the current research, we sought to revisit and reassess classics on default and framing effects by embarking on preregistered high-power replications and extensions of two impactful studies on default effects: Johnson and Goldstein (2003) and Johnson et al. (2002). The first study by Johnson and Goldstein (2003) was an early demonstration of default effects. The study found that people were more likely to register as organ donors when the default option was to register. Johnson and colleagues (2002) contrasted default effects against framing effects and found that default effects prevailed, and that framing did not change the participants' tendency to select the default over alternatives. We investigated these foundational studies.

\section{Default Effect}

Early demonstrations of default effect were in the context of auto-insurance choices made in New Jersey and Pennsylvania, when each state had a different policy regarding the right to sue for damages in auto accidents (Johnson et al., 1993). New Jersey residents had low insurance 
premiums yet could acquire an additional right to sue at an additional cost. Pennsylvanian residents by default had the right to sue, but they could opt out of this right and pay a lower insurance premium. For instance, Johnson and colleagues (1993) found that $75 \%$ of Pennsylvania auto-insurance consumers paid the higher premium and retained their right to sue. In comparison, only $20 \%$ of New Jersey auto-insurance consumers actively chose to pay the additional premium and obtain the right to sue. Researchers have since found support for the default effect in a variety of contexts related to health, retirement saving, organ donation, sustainability, insurance coverage, electricity consumption, charitable giving, and many other decision-making domains (Abadie \& Gay, 2006; Benartzi \& Thaler, 1999; Cronqvist \& Thaler, 2004; Ebeling, 2013; Jachimowicz et al., 2019; Madrian \& Shea, 2001; Shealy \& Klotz, 2015) ${ }^{1}$. While a few studies failed to support default effects (Abhyankar et al., 2014; Everett et al., 2015; Keller et al., 2011; Reiter et al., 2012), a recent meta-analysis noted substantial variations in the efficacy of the default effects (Jachimowicz et al., 2019); for instance, defaults in consumer domains were more effective, while defaults in environmental domains were less effective (Jachimowicz et al., 2019).

\section{Framing Effects}

People's decisions are also influenced by the way a decision scenario is framed-whether by using different wordings, settings, or situations (Brewer \& Kramer, 1986; De Martino, Kumaran et al., 2006; Fagley \& Miller, 1987; Gamliel \& Kreiner, 2013; Huber et al., 1987; Kramer, 1989; Kühberger, 1998; Levin \& Gaeth, 1988; Piñon \& Gambara, 2005; Puto, 1987; Rothman \& Salovey, 1997). Johnson et al. (2002) tested the action framing effects of a decision

\footnotetext{
${ }^{1}$ Although not directly relevant to the current study, researchers have offered a variety of explanations for default effects (e.g., Brown \& Krishna, 2004; Huh et al. 2014; Johnson \& Goldstein, 2003; McKenzie et al., 2006)
} 
by manipulating whether participants were asked to select (positive frame) or reject (negative frame) an option. Participation rates in the positively framed condition were higher than the negatively framed condition. In this case, the positive or negative framing greatly influenced people decisions. The findings are consistent with the view that positive dimensions of a choice are weighted more when selecting an option whereas the negative dimensions are weighted more when rejecting an option (Shafir et al., 1993).

\section{Present research}

We selected Johnson and Goldstein (2003) and Johnson et al. (2002) as our replication targets for three reasons: each is foundational, has been highly influential in academia (Kahneman, 2003; Kruglanski \& Gigerenzer, 2011; Weber \& Johnson, 2009), and has been highly influential in practice for policymaking.

Johnson and Goldstein's (2003) work was the first to demonstrate the use of defaults in an organ donation scenario, and at the time of writing this article the paper has been cited more than 2000 times. In the original study, the experimenters varied whether the donor or non-donor status was the default option. Organ donation rates were higher when the default option was to donate $(82 \%)$ than when the default option was to not donate $(42 \%)$. These findings have influenced public policy decisions; Argentina (La Nacion, 2005), Uruguay (Trujillo, 2013), Chile (Zúñiga-Fajuri, 2015), England (English et al., 2019), and Wales (Griffiths, 2013; Madden et al., 2020) have adopted default organ-donor status policies. Organ donation statistics from the Organization for Economic Cooperation and Development (OECD) countries show that, on average, organ donation rates are higher in countries where the default option is to donate (OptOut system) than in countries where the default option was not to donate (Opt-In system) (Li \& Nikolka, 2016). 
To the best of our knowledge, Johnson et al. (2002) were the first to investigate the interaction of framing of action (we refer to this framing effect here as an action framing effect) ${ }^{2}$ and default effects in people's decisions. In the original study, the researchers asked participants whether they would like to be notified about future health surveys after they completed an online health questionnaire (Johnson et al., 2002). The experimenters varied whether the default selection was to receive these future notifications, not to receive these future notifications, or neither. They also varied whether the options were framed positively ("Notify Me") or negatively ("Do Not Notify Me"). Consistent with the default effect, participants were more inclined to be notified when participation was the default. Although the framing manipulation was not significant as a predictor of participants' decision to receive these future notifications, the pattern of responses showed that participants in the positive framing conditions consented to receive health-related information at a higher rate than participants in the negative framing conditions (Johnson et al., 2002).

We embarked on direct well-powered replications of these two classic findings with two primary goals. First, we sought to revisit and reexamine the robustness of the basic default effect reported in the well-known organ donation decision scenario by Johnson and Goldstein (2003). Second, to build on these findings we sought to also contrast default and framing effects, replicating and extending the design used in Johnson et al. (2002).

\section{Effect Sizes in target articles}

The chosen target studies did not report effect sizes. We reanalyzed the data and conducted logistics regression analysis to calculate odds-ratios with a $95 \%$ confidence interval

\footnotetext{
${ }^{2}$ For an action framing effect, the presentation of a scenarios varies in the framing of the action (e.g., to select vs. to reject).
} 
for the regression coefficients as a measure of effect size. The effect sizes of the original studies are summarized in Table 9 (for detailed results, see Table S7 and Table S8 in the supplementary materials).

\section{Extensions}

In addition to the direct replications, we also performed two extensions. First, we investigated whether the permanence of the decision affects default effects. In particular, half the study participants were told that their organ donation-related decision was valid for three years, and the other half of participants were not provided with any additional information about the permanence of their decision. We based our extension on Van Dalen and Henkens (2014) who found that organ donation rates were higher when the option was temporary and would have to be renewed than when the default option was to donate. Based on these results, we investigated the presumed permanence (temporary vs. permanent) consent in Johnson and Goldstein (2003) scenario. In line with previous work, we predicted a higher organ donation participation rate when the choices were framed as temporary (i.e., the decision can be revised in five years) rather than permanent. Second, we added a conceptual replication of Johnson et al. (2002). We applied their experimental design involving framing and default effects to the organ-donation scenario in Johnson and Goldstein (2003). This replication was meant to further test the generalizability of their findings regarding the interaction of default and framing effects.

\section{Method}

\section{Process}

We crowdsourced the replication and extension effort using two teams of two authors. Both teams were supervised by two other experienced authors. Each team worked independently to conduct their own in-depth analysis of the chosen target articles and wrote detailed pre- 
registrations aiming for a very close replication and adding additional extensions. Data collection was then conducted separately for each team using a different sample. Thus, the two data collections tested two independent extensions: the effect of choice permanence (Sample 1) and the conceptual replication of Experimental 2 of Johnson et al. (2002) (Sample 2).

\section{Pre-registrations and open data/code}

In both data collections, we first preregistered the experiment on the Open Science Framework (OSF) and data collection was launched after registration. Pre-registration, disclosures, power analyses, and all materials are available in the Supplementary Materials. These, together with datasets and analysis code, were made available on the OSF at https://osf.io/8wd2b/. All measures, manipulations, and exclusions for this investigation are reported, and data collection was completed before analyses. Pre-registrations are available on the OSF: Group A - https://osf.io/mhwbe/, Group B - https://osf.io/j4rpc/.

\section{Participants and power analysis}

The present investigation includes two simultaneously collected data samples. For both the samples, we recruited participants from the United States via CloudResearch platform running on Amazon Mechanical Turk. Participants could participate in only one of these.

A priori power analysis indicated that a total sample of 156 participants was sufficient to obtain $95 \%$ power (at $\alpha=.05$ ) to detect the smallest effect reported among the original studies $(O R=1.86$; see the supplementary material for more details on the power analysis $)$.

Since our replication study also involved additional extension hypotheses across two samples, we recruited 954 and 966 participants across two replication two teams, respectively. We, therefore, combined the two samples for the data analysis, which amounted to a total of 
2011 participants. Following the preregistered exclusion criteria, we excluded 91 participants based on English proficiency, self-reported seriousness, knowledge of hypothesis, survey completion, and place of residence (see supplementary material for details). Data were analyzed from the remaining 1920 participants $\left(N 1=954 ; N 2=966 ; M_{\text {age }}=38, S D=11.85 ; 52 \%\right.$ female $)$. The power sensitivity analysis based on our final sample size indicates that each of our final samples has a minimum of $80 \%$ power (at $\alpha=.05$ ) to detect an effect size $\mathrm{OR}=1.54$.

\section{Materials and Procedure}

The procedure involved two parts. In the first part, participants read about an organ donation scenario from Johnson and Goldstein (2003). In the second part, participants responded to the scenario from Experiment 2 of Johnson et al. (2002). After completing both parts of the survey, participants provided their demographic information, and they were debriefed at the end of the study. We provide a comparison of the target article sample and the replication samples in Table S2. Participants in Sample 1 were part of a choice permanence extension. In this regard, Sample 1 participants in the first of the experiment were randomly assigned to one of two between-participants conditions: the direct replication of Johnson and Goldstein (2003) or the temporary organ donation extension condition.

\section{Part 1: Organ Donation}

In part 1 , participants were randomly assigned to 1 of 3 between-participants conditions (defaults: Opt-In vs. Opt-Out vs. No-Default). For example, participants in the "Opt-Out" condition read:

"Imagine that you have just moved to a new state and are currently filling out the required online registration forms when you are asked to indicate your organ donor 
status. The default in this state is that you ARE automatically enrolled to be an organ donor. You are given the choice of whether to confirm or to change this status. Please select an option."

After reading the passage, participants had to choose either "Yes - I want to be an organ donor" or "No - I do not want to be an organ donor." In the Opt-Out condition, the "Yes" option was pre-selected. Table 1 documents the format of the display of choices across experimental conditions. So, participants who consented to organ donation just had to click "Next" at the bottom of the page, whereas participants who did not wish to be an organ donor had to click the option "No" before clicking "Next." In the Opt-In condition, the "No" option was pre-selected. So, participants who consented to organ donation had to click the option "Yes" before proceeding, whereas participants who did not wish to be an organ donor just had to click "Next." In the No-Default condition, participants read:

"Assume you moved to a new state, therefore, you need to select enrollment as an organ donor. Please choose your preferred organ donor status:"

Participants in this No-Default condition saw the same binary response options without a pre-selected default. So, they had to actively select "Yes" or "No" before clicking "Next" to proceed. After completing part 1, participants moved on to part 2. 
Table 1. Study stimuli for the direct replication of Johnson \& Goldstein (2003)

\author{
[Introduction for participants in Opt-Out/Opt-in Conditions]: \\ Imagine that you have just moved to a new state and are currently filling out the required \\ online registration forms when you are asked to indicate your organ donor status. The default \\ in this state is that you ARE automatically enrolled to be an organ donor. You are given the \\ choice of whether to confirm or to change this status. Please select an option.

\section{[Opt-out]:} \\ Assume you moved to a new state in which the default is that you are an organ donor, you are \\ therefore by default enrolled as an organ donor. Please choose your preferred organ donor \\ status: \\ - Yes-I want to be an organ donor \\ No-I do not want to be an organ donor
}

\title{
[Opt-in]:
}

Assume you moved to a new state in which the default is that you are not an organ donor, you are therefore by default not enrolled as an organ donor. Please choose your preferred organ donor status:

Yes- I want to be an organ donor

- No-I do not want to be an organ donor

\section{[No-default]:}

Assume you moved to a new state, therefore, you need to select enrollment as an organ donor. Please choose your preferred organ donor status.

Yes- I want to be an organ donor

No-I do not want to be an organ donor

\section{Part 2: Survey Subscription}

In part 2, participants were randomly assigned to 1 of 6 conditions in a 2 (framing:

Positive vs. Negative) $\times 3$ (default option: Opt-In vs. Opt-Out vs. No-Default) between-

participants design (see Table 2 for details). At the beginning of Part 2, participants read the following instruction:

"Typically, regardless of your organ donor decision, the state online systems ask you to answer a number of health questions. Please answer the following. All the data will be kept completely confidential." 
Participants then answered four generic questions on their health in general (for details, see Table S4 supplementary section). Participants then read:

"You are almost at the end of the survey. Thank you for taking part. Would you be interested in being notified about other policy/health-related surveys? (If yes, we will contact you through MTurk using your MTurk worker ID)"

Participants answered by selecting "Yes" or "No." Each condition had a positive ("Notify me about more health surveys.") or negative (“Do NOT notify me about more health surveys.") framing. In positively framed Opt-Out conditions, the 'yes' response was pre-selected. In positively framed Opt-In conditions, the 'No' response was pre-selected. In negatively framed Opt-Out conditions, the 'No' response was pre-selected. In negatively framed Opt-in conditions, the 'yes' response was pre-selected.

Table 2. Study stimuli for the direct replication of Johnson et al. (2002)

\section{[Introduction]:}

Typically, regardless of your organ donor decision, the state online systems ask you to answer a number of health questions. Please answer the following. All the data will be kept completely confidential.

You are almost at the end of the survey. Thank you for taking part. Would you be interested in being notified about other policy/health-related surveys? (If yes, we will contact you through MTurk using your MTurk worker ID)

\section{[Positive frame, Opt-out]:}

Notify me about more health surveys.
- Yes
No

\section{[Positive frame, Opt-in]:}

Notify me about more health surveys.
Yes
- No

[Positive frame, No-default]:

Notify me about more health surveys.

$\bigcirc$ Yes 


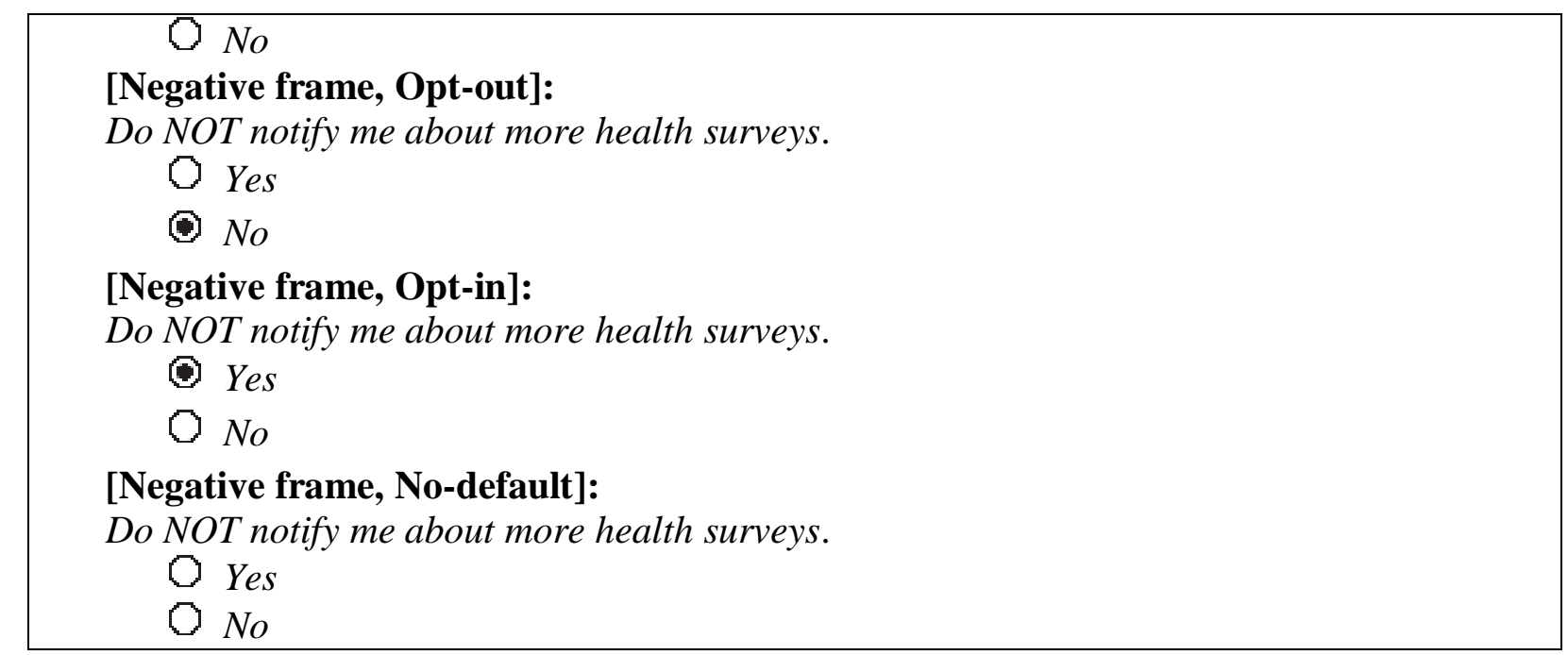

\section{Extensions}

Extension 1: The effect of choice permanence.

Participants in Sample 1 were part of the choice-permanence extension. As such, participants in Sample 1 were randomly assigned to one of two between-participants conditions (temporary or permanent). Participants assigned to the temporary conditions took the same survey as those in the permanent conditions - only they received the following additional instruction at the beginning of part 1 of the study:

"Please note: Your organ donor authorization, if granted, would be for 3 years only, meaning that after 3 years you will be asked to reconfirm your organ donor decision."

Participants in the permanent conditions had no additional instructions.

Extension 2: Conceptual replication of Experimental 2 of Johnson et al. (2002).

All the participants in Sample 2 took part in a different extension. Immediately after completing Part 1 of the study but just before Part 2, participants read the following instructions (see Table 3 for details): 
"Would you like to receive further information about organ donation through MTurk? If you indicate your approval, we'll contact you through MTurk using your worker ID with further information about organ donation."

These participants were randomly assigned to 1 of 6 conditions in a 2 (framing: Positive vs. Negative) $\times 3$ (default option: Opt-Out vs. Opt-In vs. No-Default) between-participants design (for details, see Table S6 in the supplementary section). After reading the above instruction, participants selected "Yes" or "No" to a question asking for consent to receiving further information on organ donation. Each of the default conditions involved either a positive ("Send me more information about organ donation") or negative ("Do NOT send me more information about organ donation") framing. The responses were pre-selected in the Opt-In and Opt-Out default conditions mirroring the experimental design of Experiment 2 of Johnson et al. (2002). In positively framed Opt-Out conditions, the 'yes' response was pre-selected. In positively framed Opt-In conditions, the 'No' response was pre-selected. In negatively framed Opt-Out conditions, the 'no' response was pre-selected. In negatively framed Opt-In conditions, the 'yes' response was pre-selected. 
Table 3. Study stimuli for the on conceptual replication of Johnson et al. (2002)

\section{[Introduction]:}

Typically, regardless of your organ donor decision, the state online systems ask you to answer a number of health questions. Please answer the following. All the data will be kept completely confidential.

You are almost at the end of the survey. Thank you for taking part. Would you be interested in being notified about other policy/health-related surveys? (If yes, we will contact you through MTurk using your MTurk worker ID)

[Positive frame, Opt-out]:

Send me more information about organ donation.
- Yes
No

\section{[Positive frame, Opt-in]:}

Send me more information about organ donation.

Y Yes

- No

\section{[Positive frame, No-default]:}

Send me more information about organ donation.

Y Yes

No

[Negative frame, Opt-out]:

Do NOT send me more information about organ donation.

$\mathrm{O}$ Yes

- No

[Negative frame, Opt-in]:

Do NOT send me more information about organ donation.

O Yes

No

[Negative frame, No-default]:

Do NOT send me more information about organ donation.

Yes

No

\section{Data Transformations}

Both Part 1 and Part 2 of the replication study collected the participants' responses in a binary format (Yes/No). In the organ donation scenario, we coded the answer "Yes" (i.e., 
consenting to donate organs) as ' 1 '. We coded the response "No" (i.e., dissenting to donate organs) as ' 0 '. In Part 2 , the responses that indicate the consent for participation were coded as “1," whereas non-participation was coded as "0". Coding of the answers for the choice permanence extension and the conceptual replication of Johnson et al. (2002) followed the same response coding procedure as that of Part 1 and Part 2, respectively. Consistent with previous literature, we define default effects as the difference in participation rates between the Opt-Out condition versus that in the Opt-In condition. We then calculated the odds-ratio for the regression coefficients as a measure of effect size with a $95 \%$ confidence interval.

\section{Analysis}

Data were analyzed using R. Data were fit to logistic regression models using the $\mathrm{glm}$ function (with "binomial("logit")" as the family). In Part 1, we report the results from 2-sample test for equality of proportions (comparing the participation rate across different defaults). We analyzed the data for Part 2 with a $2 \times 3$ binomial logistic regression, with framing (Positive vs. Negative) and default (Opt-In vs. Opt-Out vs. No-Default) and interaction terms of framing and defaults as predictors of the respondent's decision to participate $(1=Y e s ; 0=N o)$.

For testing the effect of choice permanence on organ donation rate, we conducted chisquare tests comparing the participation rate across temporary and permanent conditions. In the second extension, we conducted the same analysis as for part 2 of the study.

\section{Replication evaluation}

We evaluated findings in our replication effects using the criteria set by LeBel, Vanpaemel et al. (2019) (see Table S15 and Figure S2 in the supplementary material). Table 4 provides a classification of the replications using the LeBel et al. (2019) criteria. We summarize the present replications as very close. 
Table 4. Classification of replications based on LeBel et al. (2019)

\begin{tabular}{ll}
\hline Design facet & Replication study \\
\hline IV operationalization & Same \\
DV operationalization & Same \\
IV stimuli & Same \\
DV stimuli & Same \\
Procedural details & Similar \\
Physical settings & Different \\
Contextual variables & Different \\
\hline Replication classification & Very close replication \\
\hline
\end{tabular}

\section{Results}

We provide a summary of the findings in Table 9 . We present complete descriptive statistics across the two samples in Table 5 (also see Table S10 in the supplementary materials).

Table 5. Descriptive table of the participation rates.

\begin{tabular}{|c|c|c|c|c|}
\hline \multirow{2}{*}{ Replication Study } & \multirow{2}{*}{\multicolumn{2}{|c|}{ Experimental Conditions }} & \multicolumn{2}{|c|}{$\begin{array}{c}\text { Combined replication } \\
\text { sample }\end{array}$} \\
\hline & & & $\mathbf{n}$ & $\begin{array}{c}\text { Participation } \\
\text { rate }\end{array}$ \\
\hline \multirow{3}{*}{$\begin{array}{l}\text { Replication of } \\
\text { Experiment } 1 \text { from } \\
\text { Johnson \& Goldstein } \\
(2003)\end{array}$} & \multicolumn{2}{|c|}{ Opt-in default } & 488 & $62.5 \%$ \\
\hline & \multicolumn{2}{|c|}{ Opt-out default } & 476 & $73.5 \%$ \\
\hline & \multicolumn{2}{|c|}{ No-default (no default) } & 482 & $69.7 \%$ \\
\hline \multirow{6}{*}{$\begin{array}{l}\text { Replication of } \\
\text { Experiment } 2 \text { from } \\
\text { Johnson, Bellman \& } \\
\text { Lohse (2002) }\end{array}$} & \multirow{2}{*}{ Opt-in default } & Positive Framing & 324 & $88.6 \%$ \\
\hline & & Negative Framing & 324 & $33.6 \%$ \\
\hline & \multirow{2}{*}{ Opt-out default } & Positive Framing & 321 & $93.1 \%$ \\
\hline & & Negative Framing & 319 & $27.6 \%$ \\
\hline & \multirow{2}{*}{ No-default (no default) } & Positive Framing & 320 & $93.4 \%$ \\
\hline & & Negative Framing & 312 & $25.3 \%$ \\
\hline
\end{tabular}

Note. $N=1920$; 


\section{Part 1: Replication of Johnson and Goldstein (2003)}

Consistent with the original study, participants in the Opt-Out condition consented to organ donation at a higher rate $(73.5 \%)$ than participants in the Opt-In condition $(62.5 \%)($ Chisquared test: $\chi^{2}(1)=12.96, p<.001$, Odds ratio $(\mathrm{OR})=1.67,95 \%$ CI $[1.27,2.19]$ (see Figure 1). This result was consistent across both samples (See Table S11 for complete results). Also, participants in the No-Default condition consented to organ donation at a higher rate $(69.7 \%)$ than participants in the Opt-In condition $(62.5 \%)\left(\chi^{2}(1)=5.31, p=.021, \mathrm{OR}=1.38,95 \% \mathrm{CI}\right.$ $[1.06,1.80]$ ) with slight deviations between the two samples (See Table S11 for complete results). Also see Table 6 for the results based on logistic regression.

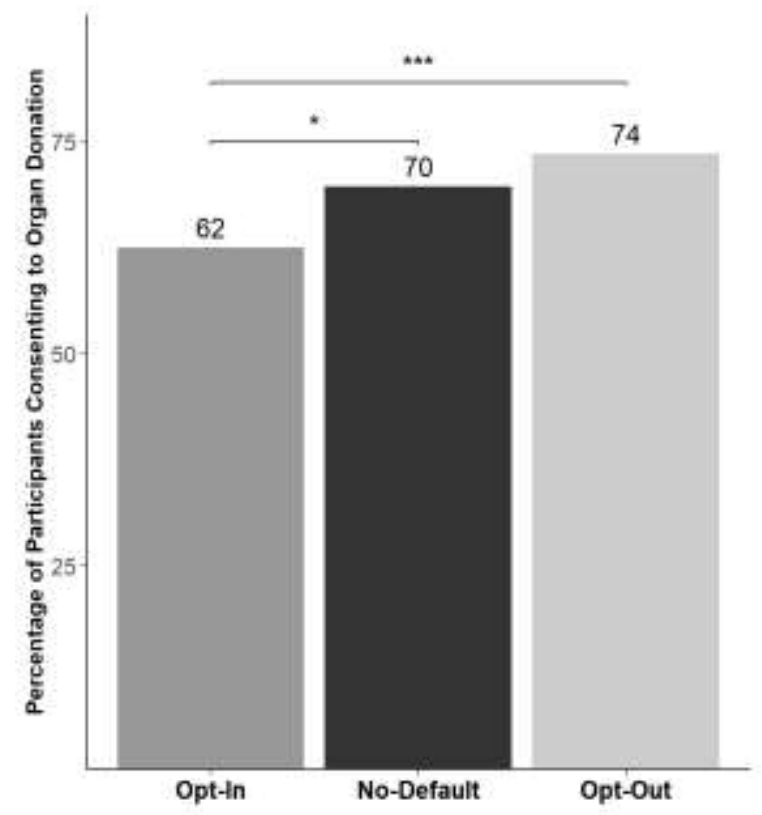

\section{Figure 1.}

Results of direct replications of Johnson and Goldstein (2003).

Percentage of participants consenting to organ donation by condition across both samples. Note. $* p<.05, * * p<.01, * * * p<.001$ 


\section{Table 6.}

Summary of the replication results of Part 1 (Johnson \& Goldstein, 2003) based on logistic regression analysis

\begin{tabular}{lccccc}
\hline Predictor & Estimate & $\boldsymbol{S E}$ & $\boldsymbol{Z}$ & $\boldsymbol{p}$ & OR [95\% CI] \\
\hline Intercept & 0.51 & 0.09 & 5.46 & $<.001$ & $1.67[1.39,2.00]$ \\
Default: No-Default - Opt-In & 0.32 & 0.14 & 2.37 & 0.018 & $1.38[1.06,1.80]$ \\
Default: Opt-Out - Opt-In & 0.51 & 0.14 & 3.65 & $<.001$ & $1.67[1.27,2.19]$ \\
\hline
\end{tabular}

Note. Estimates represent the odds of the dependent variable $=$ " 1 " vs. " 0 ".

\section{Part 2: Replication of Johnson, Bellman, and Lohse (2002)}

We present the results of the regression analysis in Table 7 (Figure 2), and descriptive statistics in Table S9 in the supplementary section.

\section{Default effects}

We failed to find support for differences in rates of consent to receive health-related information between the Opt-Out condition (60.5\%) and the Opt-In condition $(61.1 \%)(b=-.29$, $p=.095, \mathrm{OR}=0.75,95 \% \mathrm{CI}[0.53,1.05])$; that is, we found no support for a default effect. This result was consistent across both samples (See Table S11 for complete results). Participants in the No-Default $(59.8 \%)$ condition, moreover, consented to receive health-related information at a lower rate than participants in Opt-In (61.1\%) condition $(b=-0.41, p=.021, \mathrm{OR}=0.67,95 \% \mathrm{CI}$ $[0.47,0.94])$.

\section{Framing effects}

Participants in the positive framing condition consented to receive health-related information $(91.7 \%)$ at a higher rate than participants in the negative framing condition $(28.9 \%)$ $(b=2.74, p<.001, \mathrm{OR}=15.61,95 \% \mathrm{CI}[10.31,23.63])$. 


\section{Exploratory: Default effects as a function of frames}

We proceeded to conduct additional exploratory (not preregistered) analyses examining the interaction between framing and defaults. We found support for an interaction (see Table 7). We considered two sets of interactions: 1) (Positive - Negative) $\times($ No-default - Opt-In); 2) (Positive - Negative $) \times($ Opt-Out - Opt-In) .

For the (Positive - Negative $) \times($ No-default - Opt-In) interaction, we looked at the consent rates between the No-Default and Opt-In conditions across the positive and negative frame $(b=1.01, p=.003, \mathrm{OR}=2.76,95 \% \mathrm{CI}[1.43,5.32])$. Within positive framing conditions, participants in the No-Default condition (93.4\%) consented to receive health-related information at a higher rate than participants in the Opt-In condition (88.6\%) (see Table S12 and Table S13 in the supplementary materials). The pattern of results was in the opposite direction in the negative framing conditions: participants in the No-Default condition (25.3\%) consented to receive health-related information at a lower rate than participants in the Opt-In condition $(33.6 \%)$.

The results were similar for the (Positive - Negative) $\times($ Opt-Out - Opt-In) interaction $(b$ $=0.85, p=.010, \mathrm{OR}=2.35,95 \% \mathrm{CI}[1.23,4.49])$. Within positive framing conditions, participants in the Opt-Out condition $(93.1 \%)$ consented to receive health-related information at a higher rate than participants in the Opt-In condition $(88.6 \%)$. The pattern of results was in the opposite direction within the negative framing conditions: participants in the Opt-Out condition $(27.6 \%)$ consented to receive health-related information at a lower rate than participants in the Opt-In condition (33.6\%). 


\section{Table 7}

Summary of the replication results of Part 2 (Johnson, Bellman, \& Lohse, 2002) based on logistic regression analysis

\begin{tabular}{|c|c|c|c|c|c|c|c|c|}
\hline \multirow{2}{*}{ Predictor } & \multicolumn{4}{|c|}{ Model 1} & \multicolumn{4}{|c|}{ Model 2} \\
\hline & Estimate & $Z$ & $p$ & OR $[95 \% \mathrm{CI}]$ & Estimate & $Z$ & $p$ & OR $[95 \% \mathrm{CI}]$ \\
\hline Intercept & $-0.84(0.11)$ & -7.65 & $<.001$ & $0.43[0.35,0.53]$ & $-0.68(0.12)$ & -5.78 & $<.001$ & $0.51[0.40,0.64]$ \\
\hline Framing: Positive - Negative & $3.31(0.14)$ & 24.14 & $<.001$ & $27.27[20.97,35.88]$ & $2.73(0.21)$ & 12.96 & $<.001$ & $15.30[10.23,23.40]$ \\
\hline Default: No-Default - Opt-In & $-0.12(0.15)$ & -0.81 & 0.417 & $0.89[0.66,1.19]$ & $-0.40(0.18)$ & -2.29 & 0.021 & $0.66[0.47,0.94]$ \\
\hline Default: Opt-Out - Opt-In & $-0.05(0.15)$ & -0.35 & 0.724 & $0.95[0.71,1.27]$ & $-0.29(0.17)$ & -1.66 & 0.096 & $0.75[0.54,1.05]$ \\
\hline \multicolumn{9}{|l|}{ Interaction term: } \\
\hline (Positive - Negative $) \times($ No-Default-Opt-In) & & & & & $1.00(0.33)$ & 3.02 & 0.003 & $2.74[1.43,5.35]$ \\
\hline (Positive - Negative $) \times($ Opt-Out - Opt-In $)$ & & & & & $0.85(0.33)$ & 2.57 & 0.010 & $2.33[1.23,4.49]$ \\
\hline
\end{tabular}

Note. Estimates represent the odds of the dependent variable $=$ "1" vs. "0". Standard errors are reported within the brackets. 

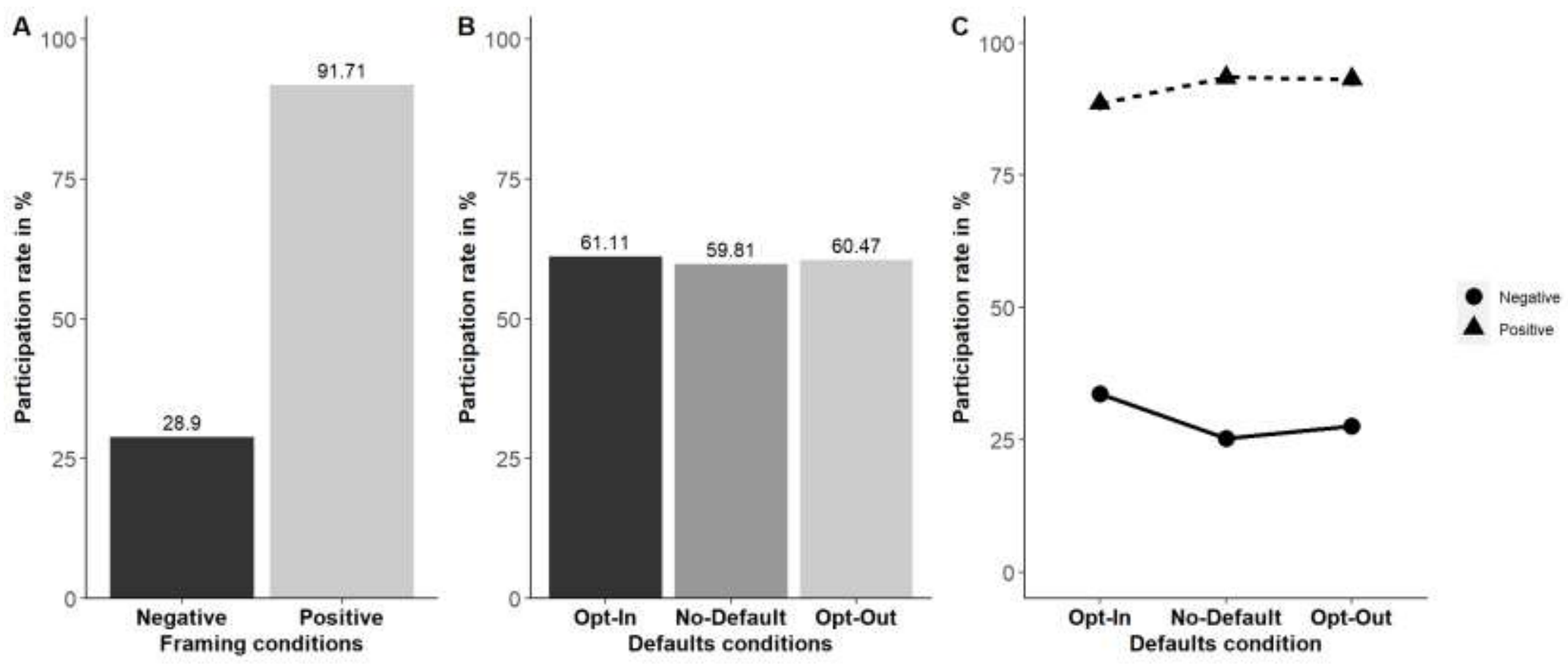

\section{Figure 2.}

Results of direct replication of Johnson et al. (2002).

Percentage of participants who agreed to be notified about health-related surveys in the future. (A) Percentage of participants participating in the health survey by frame. $(B)$ Percentage of participants participating in the health survey by default conditions. $(C)$ Percentage of participants participating in the health survey by frame and conditions.

Note. $n s>.05, * p<.05, * * p<.01, * * * p<.001$. 


\section{Extensions}

\section{Extension 1: Temporary vs. Permanent Choice}

We found no evidence that organ donation rates varied between the temporary $(70.3 \%)$ and the permanent conditions $(65.8 \%)\left(\chi^{2}(1, N=954)=1.94, p=.163 ; d=0.11,95 \%\right.$ CI $[-0.04$, 0.26]; Figure 3). Additionally, we looked at differences within the No-Default condition, and again failed to find evidence for differences (temporary: $74.7 \%$; permanent: $67.3 \% ; \chi^{2}(1, N=$ $320)=1.78, p=.182, d=0.20,95 \%$ C.I. $[-0.07,0.47])$.

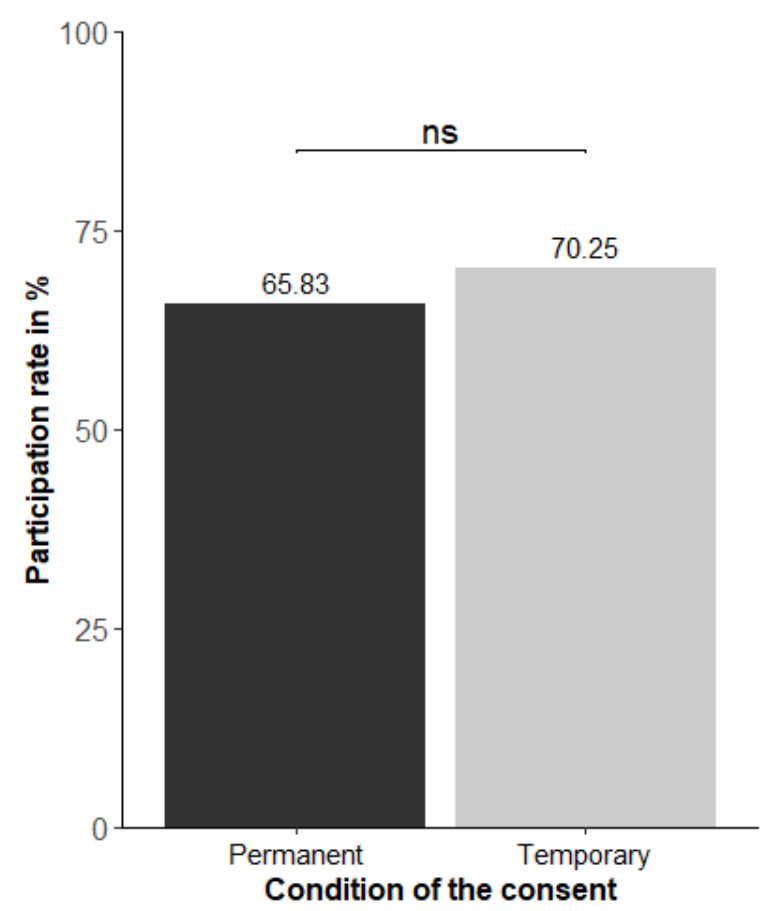

\section{Figure 3.}

Results of Extension 1. Percentage of participants who consented to organ donation between permanent vs. temporary choice scenarios.

Note. $n s p>.05$. 
Extension 2: Conceptual replication of Experimental 2 of Johnson et al. (2002)

We summarized the regression analysis in Table 8 and Figure 4, and descriptive statistics are provided in Table S14 in the supplementary.

Participants in the Opt-Out condition consented to receive organ donation-related information (50.2\%) at a higher rate than participants in Opt-In condition $(37.3 \%)(b=0.59 ; p=$ $.012, \mathrm{OR}=1.81,95 \% \mathrm{CI}[1.14,2.87])$. We found no evidence that consent rate varied between participants in the No-Default condition (46.6\%) and participants in the Opt-In condition $(37.3 \%)(b=0.39 ; p=.092, \mathrm{OR}=1.48,95 \% \mathrm{CI}[0.94,2.32])$. Participants in the positive framing condition consented to receive organ donation-related information (24.9\%) at a lower rate than participants in negative framing condition $(64.6 \%)(b=1.82 ; p<.001, \mathrm{OR}=0.16,95 \%$ CI $[0.10,0.27])$. We found no evidence that results of defaults on participation rate vary as a function of frame (see Table 8).

\section{Summary of replication findings}

We replicated the default effects from Johnson and Goldstein (2003). In Part 1 of our study, participants consented to donate their organs at a higher rate when they had to opt out relative to when they had to opt in. We, however, failed to replicate the default effects in Johnson et al. (2002). In Part 2 of our study, we found no evidence that consent to be notified about health-related surveys varied between the opt-out and opt-in conditions. Furthermore, we found that people in positively framed scenarios consented to receive health-related information at a higher rate than participants in negatively framed scenarios. This result deviated from the findings of Johnson et al. (2002) that showed no framing effects.

We followed LeBel et al.'s (2019) framework for the evaluation of our replication using three factors: (a) whether a signal was detected (i.e., the confidence interval for the replication 
Effect Size (ES) excludes one), (b) consistency of the replication ES with the original study's ES, and (c) precision of the replication's ES estimate (see Figure S2 in the supplementary material). We summarized our evaluations of the replications' findings based on LeBel et al.' s (2019) replication evaluation framework in Table 9 (see Figure 5). 

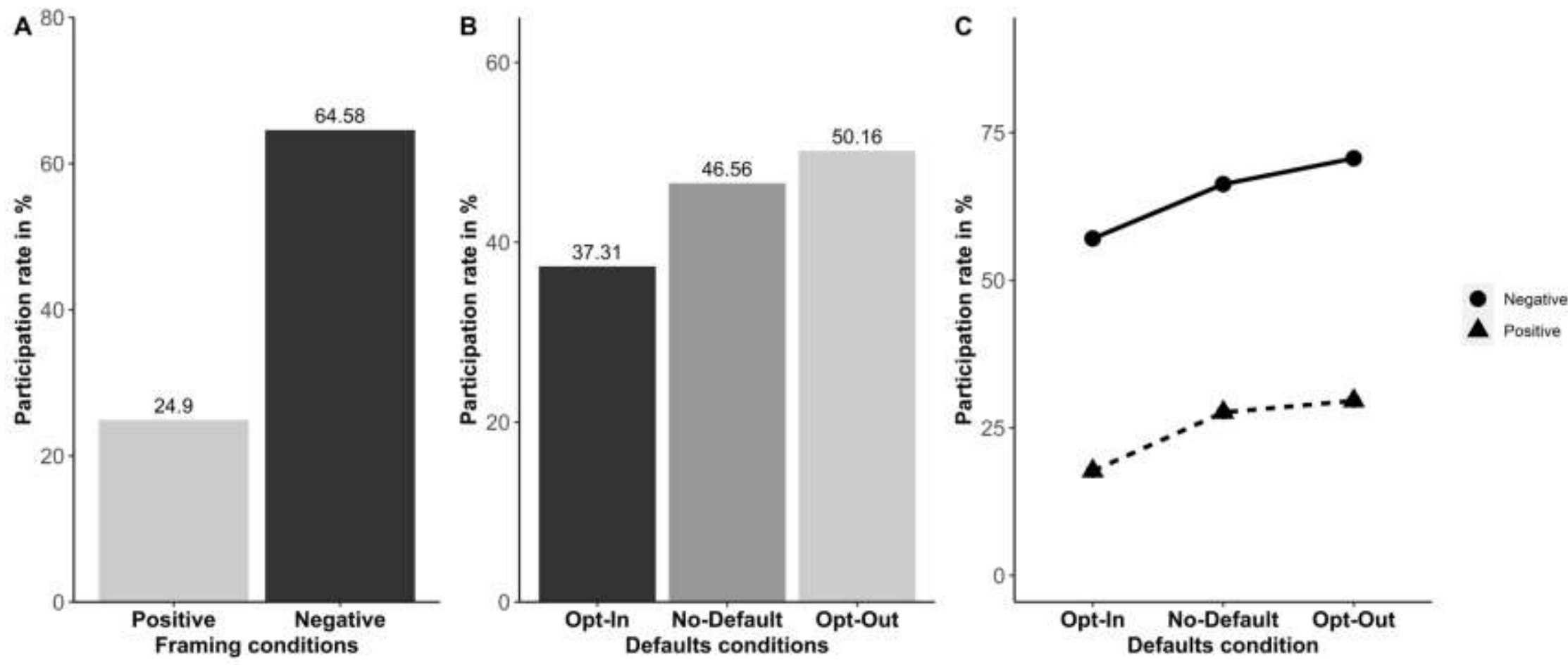

\section{Figure 4.}

Extension 2: Percentage of participants who agreed to be notified about further information about organ donation in the future. $(A)$ Participation rates by frame. $(B)$ Participation rates by default conditions. (C) Participation rates by frame and conditions. Note. $n s>.05, * p<.05, * * p<.01, * * * p<.001$. 


\section{Table 8}

Summary of the replication results of Extension 2 (conceptual replication of Johnson, Bellman, \& Lohse, 2002) based on logistic regression analysis

\begin{tabular}{l|cccc|cccc}
\hline \multirow{2}{*}{ Predictor } & \multicolumn{4}{|c|}{ Model 1 } & \multicolumn{4}{c}{ Model 2 } \\
\cline { 2 - 8 } & Estimate & $\boldsymbol{Z}$ & $\boldsymbol{p}$ & OR [95\% CI] & Estimate & $\boldsymbol{Z}$ & $\boldsymbol{p}$ & OR [95\% CI] \\
\hline Intercept & $0.72(0.14)$ & 5.11 & $<.001$ & $2.05[1.56,2.71]$ & $0.28(0.16)$ & 1.79 & 0.072 & $1.33[0.97,1.81]$ \\
Framing: Positive - Negative & $-1.73(0.14)$ & -12.06 & $<.001$ & $0.18[0.13,0.23]$ & $-1.82(0.26)$ & -7.04 & $<.001$ & $0.16[0.09,0.27]$ \\
Default: No-Default - Opt-In & $-0.47(0.17)$ & -2.67 & 0.007 & $0.62[0.44,0.88]$ & $-0.39(0.23)$ & 1.68 & 0.091 & $1.48[0.94,2.32]$ \\
Default: Opt-Out - Opt-In & $0.15(0.17)$ & 0.87 & 0.383 & $1.16[0.83,1.63]$ & $-0.59(0.24)$ & 2.52 & 0.011 & $1.80[1.14,2.86]$ \\
Interaction terms: & & & & & & & & \\
(Positive - Negative) $\times$ (No-Default-Opt-In) & & & & & $0.18(0.35)$ & 0.52 & 0.604 & $1.20[0.59,2.41]$ \\
(Positive - Negative) $\times$ (Opt-Out -Opt-In) & & & & & 0.21 & 0.830 & $1.07[0.53,2.17]$ \\
\hline
\end{tabular}

Note. Estimates represent the odds of the dependent variable $=$ " 1 " vs. " 0 "; $N=966$. Standard errors are reported within the brackets. 


\section{Extensions: Summary of findings}

In the first extension, we predicted that people would be more inclined to become donors when consent to organ donation is temporary. We found no evidence that consent varied between the temporary and permanent conditions.

In the second extension, we conducted a conceptual replication of Experiment 2 of Johnson et al. (2002) using the scenario from Part 1 in which participants consented to receive additional information about organ donation. We found support for the default effect: participants who had to opt out consented at higher rates than those who had to opt in. Deviating from the original study where they found no support for framing effects, we found that people in positively framed scenarios consented to receive health-related information at a lower rate than participants in negatively framed scenarios. Framing effects in our extension is opposite to those found in our direct replication of the original study scenario (Johnson et al. 2002). 


\section{Table 9}

Summary and comparison of findings of the current replication study and the target studies

\begin{tabular}{lllll}
\hline Part & Target effect & Original effect size & Replication effect size & Replication summary \\
\hline & $\begin{array}{l}\text { Default effects: No- } \\
\text { Default vs. Opt-In }\end{array}$ & $4.72[2.03,10.96]$ & $1.38[1.06,1.80]$ & Signal-inconsistent, smaller \\
$\begin{array}{l}\text { Part 1: Johnson and } \\
\text { Goldstein (2003) }\end{array}$ & $\begin{array}{l}\text { Default effects: Opt- } \\
\text { Out vs. Opt-In }\end{array}$ & $5.93[2.48,14.20]$ & $1.67[1.27,2.19]$ & Signal-inconsistent, smaller \\
\hline $\begin{array}{l}\text { Pefault effects: No- } \\
\begin{array}{l}\text { Bellman, and } \\
\text { Lohse }\end{array}\end{array}$ & $\begin{array}{l}\text { Default vs. Opt-In } \\
\text { Default effects: Opt- } \\
\text { Out vs Opt-In }\end{array}$ & $4.29[1.28,8.45]$ & $0.66[0.47,0.94]$ & $\begin{array}{l}\text { Signal-inconsistent, } \\
\text { opposite }\end{array}$ \\
\cline { 2 - 3 } & $\begin{array}{l}\text { Framing effects: } \\
\text { Positive vs. Negative }\end{array}$ & $1.86[0.76,4.57]$ & $15.30[10.23,23.40]$ & $\begin{array}{l}\text { Signal-inconsistent, } \\
\text { stronger }\end{array}$ \\
\hline
\end{tabular}

Note. Replication summary based on the criteria by LeBel et al. (2019).

\footnotetext{
${ }^{3}$ The effect size [Odds ratio] for this target study was calculated based on 2-sample test for equality of proportions.
} 


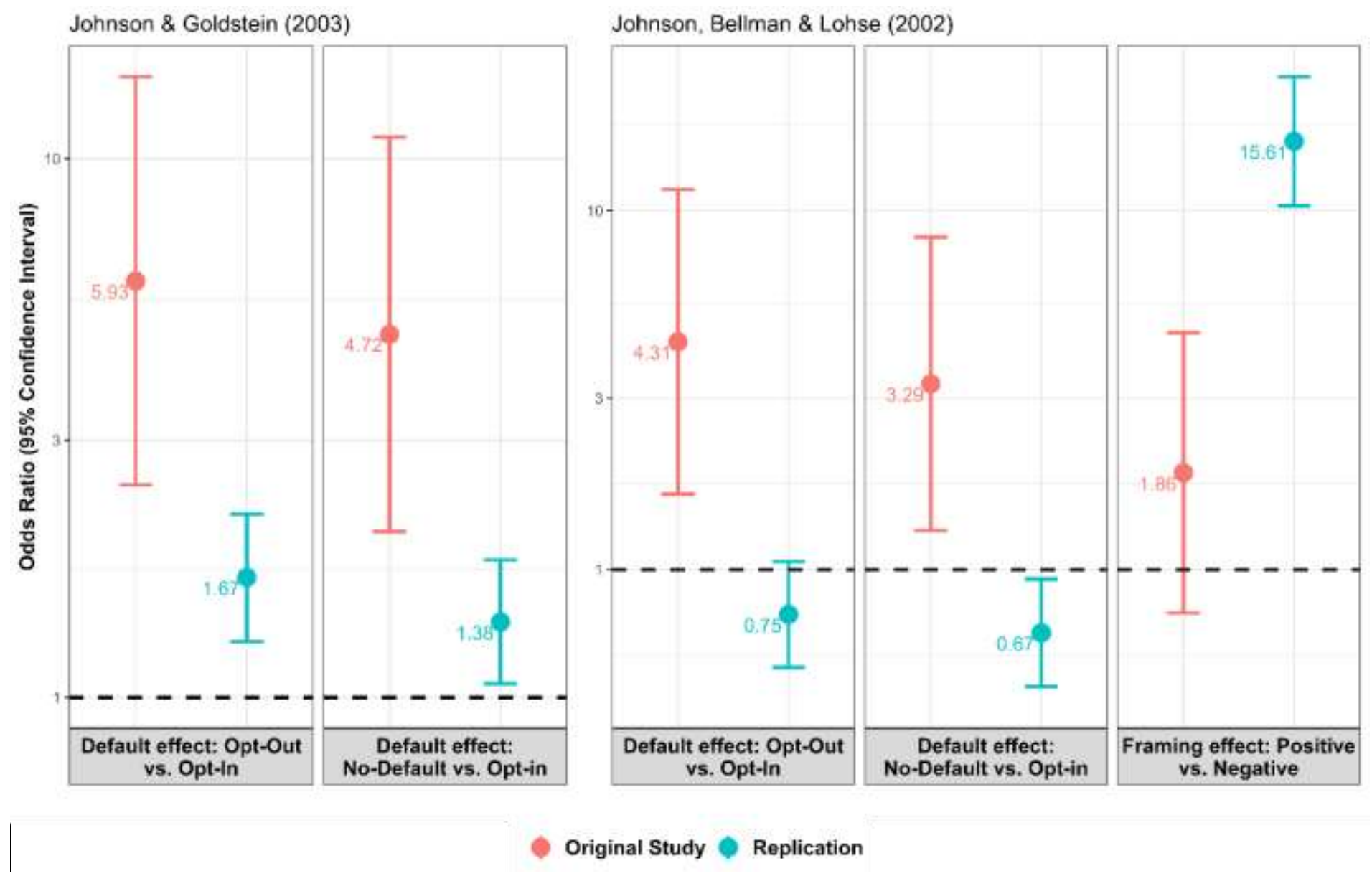

\section{Figure 5.}

Effect sizes in Johnson and Goldstein (2003), Johnson et al. (2002), and the current replication.

Estimates and confidence intervals are plotted on a natural logarithmic scale. 
Table 10

Summary of the findings of Johnson et al. (2002) across original, direct replication, and conceptual replication studies

\begin{tabular}{|c|c|c|c|c|c|c|}
\hline \multirow{2}{*}{ Predictor } & \multicolumn{2}{|c|}{ Original study's findings } & \multicolumn{2}{|c|}{ Direct replication findings } & \multicolumn{2}{|c|}{ Conceptual replication findings } \\
\hline & Signal & Directionality & Signal & Directionality & Signal & Directionality \\
\hline \multicolumn{7}{|l|}{ Default condition: } \\
\hline No-Default- Opt-In & Yes & Consistent & No & $\begin{array}{c}\text { Inconsistent - } \\
\text { Opposite direction }\end{array}$ & No & Consistent \\
\hline $\begin{array}{c}\text { Opt-Out - Opt-In } \\
\text { Framing condition: }\end{array}$ & Yes & Consistent & No & Consistent & Yes & Consistent \\
\hline Positive - Negative & No & Consistent & Yes & Consistent & Yes & $\begin{array}{c}\text { Inconsistent - } \\
\text { Opposite direction }\end{array}$ \\
\hline
\end{tabular}

Note. Directionality dimension summarizes the directional consistency of results across Default effects and Framing effects; Predicted directionality of framing effects: participants' consent rates are higher in the positive frame than negative frame condition; Predicted directionality of default effects: consent rates are higher in 'Opt-Out' and 'No-Default' experimental condition than 'Opt-In' experimental condition. Signal, indicates support for the hypothesis using null hypothesis significance testing $(p<.05)$ 


\section{Summary of findings of Johnson et al. (2002) across original, direct replication, and conceptual replication studies}

The findings across direct and conceptual replication of Johnson et al. (2002) provide mixed support to the original study's assertion. We summarize the comparison of the findings in Table 10. Both direct and conceptual replication failed to find differences in consent rates between the No-Default condition and the Opt-In condition. Only the conceptual replication found that consent rates were higher in Opt-out condition than in the Opt-In condition. Regarding the framing effects, we expected to find that participants in the positive framing condition consent at a higher rates than participants in the negative framing condition. While the original study did not find this, we found that consent rates were higher in positive frame condition than negative frame condition in our direct replication. However, in our conceptual replication, we found a framing effect in the opposite direction.

\section{General discussion}

We conducted a direct, close replication of Johnson and Goldstein (2003) and Johnson et al. (2002). In Part 1 of our study, we successfully replicated Johnson and Goldstein (2003). Participants consented to be organ donors at higher rates when they had to opt out of consent relative to participants who had to opt in. We found that participants in the No-Default condition - where no response was pre-selected — consented to organ donation at higher rates relative to participants who had to opt in. Additionally, we found that the permanence of these decisions affected people's choices.

Our replication results are consistent with Johnson and Goldstein (2003) - though the effects were smaller than those reported in the original study. The weaker effect is in line with 
recent work which found that effect sizes in large-scale studies were smaller than the estimates forecasted by academic experts and practitioners with relevant knowledge of nudge effects (DellaVigna \& Linos, 2020). Our well-powered study provides a more precise estimation of the effect size $(\mathrm{OR}=1.67,95 \% \mathrm{CI}[1.27,2.19])$ that may be useful for future meta-analyses and for policy applications.

In Part 2 of our study, our replication results of Johnson et al. (2002) were inconsistent with the original findings. Unlike the original study, we found framing effects, yet we found no evidence for default effects. Consistent with the original study, we found that participants in the positive framing conditions consented to receive organ donation information at a higher rate than participants in the negative framing condition. However, in our conceptual replication of Johnson et al. (2002) that we report as Extension 2, participants in the positive framing condition consented to receive organ donation information at a lower rate than participants in the negative framing condition.

Our results on default effects were inconsistent with the original findings in Johnson et al. (2002): we had no evidence for default effects overall. Nonetheless, we did find some indication of default effects when scenarios were framed positively. For instance, within positive framing conditions, participants in the No-Default condition and Opt-Out condition consented to receive health-related information at a higher rate than participants in the Opt-In condition. The pattern of results was in the opposite direction within the negative framing conditions: participants in the No-Default condition and Opt-Out condition consented to receive health-related information at a lower rate than participants in Opt-In condition. Interestingly, we found the consistent pattern across positive and negative frames in the conceptual replication: although these differences were not significant, participants in the No-Default condition and Opt-Out condition consented 
to receive organ donation related information at a higher rate than participants in Opt-In condition. As such, our results suggest that the stability of default effects can vary depending on the framing of the decision scenario.

There are several possible explanations for the inconsistent findings in our replications of Johnson et al. (2002). First, the failure to replicate the default effects may have been due to insufficient sample size in Johnson et al. (2002), which involved only 235 participants_about 39 participants for each experimental condition. This small sample may have led to false-positive results and inflated the effect size. Moreover, the smaller sample size in the original article may have resulted in the failure to detect the framing effects and the interaction that we found.

Second, the differences could be a result of changing preferences toward participating in online surveys. The original study was published in 2002, and the experimental scenario involved consenting to be notified about health-related surveys in the near future. People's preferences for taking part in online surveys may have changed in the last two decades. Therefore, the differences in the results could be informed by the change in peoples' preferences. Given the other successful replication in Part 1 of our study, we think this explanation is unlikely, yet we cannot rule out this possibility.

A third related explanation may be due to carry-over effects resulting from the order of the replications. The failed replication of Johnson et al. (2002) was in Part 2 and followed the unrelated organ-donation scenario in Part 1. We acknowledge that there is the slight possibility that somehow the order of execution affected the findings in Part 2. We consider this unlikely; the findings were not noise - they reflected a clear pattern of framing effects over default effect - so it would seem improbable that the slight manipulation in Part 1 triggered such a major shift from default effects to framing effects in Part 2. In our study design, we also took measures 
to mitigate carry-over effects. In Part 1, participants responded to the organ donation scenarios of Johnson and Goldstein (2003). The participants were assigned to three between-participants scenarios: Opt-Out, Opt-in, No-default. After completing Part 1 of the experiment, participants were randomly assigned to one of six between-participants conditions related to Johnson et al. (2002) in Part 2. So, we find it unlikely that a carry-over effect occurred in such a complex between-participants design. Furthermore, Samples 1 and 2 had slightly different procedures. Despite these differences, we report similar results across the sample (see Table S11 in the supplementary materials). Therefore, this possibility of carry-over effects is unlikely.

Finally, the lack of support for the default effects in the negatively framed scenarios of Johnson et al. (2002) may have been due to the fact that double-negatively framed questions (i.e., negatively framed in the Opt-in scenario) are more confusing to participants than the other conditions. However, this possibility too seems to be an unlikely explanation for the lack of default effects. First off, the original study carried the same double-negatively framed questions yet found support for default effects. While we recognize that double-negative questions may have been taxing to follow, the relatively consistent effects within negatively framed default conditions suggest otherwise. Across the three conditions with negatively-framed descriptions, the participation rates were similar: Opt-Out (28\%), Opt-In (34\%), and No-Default (25\%). The similar participation rates across default conditions within the negative frame suggest that comprehending double negatively framed questions do not explain our pattern of findings.

There are also some potential explanations for other inconsistencies we found in our replications. Interestingly, the direction of framing effects in our conceptual replication of Johnson et al. (2002) was in the opposite direction of that found in our direct replication of Johnson et al. (2002). Although this result is inconsistent with the original study, it may not be 
entirely surprising; previous work suggests that framing effects may vary across task contexts. For example, work by Zhen and Yu (2016) show that framing effect vary between vignette-based vs. reward-based decision tasks. Furthermore, previous work also found that the direction of framing effects may differ based the relative attractiveness of the alternatives (Chandrashekar et al., 2021; Chen \& Proctor, 2017; Wedell, 1997), or the degree to which decision may have personal relevance to participants (Krishnamurthy et al., 2001). Future work on framing effects may further investigate whether different task contexts modulate the direction of framing effects.

At a more theoretical level, Wedell's (1997) accentuation hypothesis perhaps best describes the pattern of current results about framing effects. Wedell (1997) argues that people have a higher need for justification in a positively framed choice than in a negatively framed choice. This higher need for justification highlights the differences between alternatives. On this account, when the overall attractiveness or benefits of participating in a health survey is high, people in the positively framed choice will choose to participate at a higher rate. Alternatively, when the overall attractiveness of participating in a health survey is lower, participants in the positively framed choice will choose to participate at a lower rate. Our results across direct and conceptual replication of Johnson et al. (2002) support this account. In the direct replication of Johnson et al. (2002) using a healthcare survey scenario, we find an overall high participation rate of $60.4 \%$ across conditions, and we found that participation rates were higher in the positive frame condition. In the conceptual replication of Johnson et al. (2002) that involved an organ donation scenario, we found an overall lower participation rate of $44.6 \%$ across experimental conditions, suggesting that the overall attractiveness of the option of consenting to receive additional information on organ donation is lower. Interestingly, we found that participation rates 
were lower in the positively framed condition. Our findings suggest that future work on the default effect may benefit from paying closer attention to the accentuation hypothesis.

\section{Conclusion}

Overall, our effort to replicate Johnson et al. (2002) contributes to the extant literature by testing the stability of default effects. Since the publication of Johnson et al. (2002), there has not been much interest in further studying framing effects (Positive vs. Negative frame) together with default effects. We believe that our findings indicate that this is a promising area for future research.

The current findings underline the importance of well-powered preregistered replications and extensions of notable findings in the judgment and decision-making literature. Our results suggest that the stability of default effects depends on the framing and context of the decision scenario and therefore hold valuable implications for the study of default effects. Although work on default effects has deservedly garnered attention from both scholars and public policy practitioners in the last two decades, our work suggests that we need a more refined and contextualized understanding of defaults' effectiveness.

We propose two main assertions. First, the effect size of default effects is likely smaller than those documented in original studies (DellaVigna \& Linos, 2020). Therefore, we need wellpowered samples to study default effects to achieve greater precision in our effect size estimates. Second, framing seems to influence the direction of default effects. Future work on default effects should be aware that people's decision frame can influence defaults' effectiveness. We hope the current replication opens up a range of theoretical and empirical work that can further future work on default effects. 


\section{Open Practices}

Open data, open materials, and double-blinded version of the original 2019 preregistrations are available here: https://osf.io/8wd2b/. 


\section{References}

Abadie, A., \& Gay, S. (2006). The impact of presumed consent legislation on cadaveric organ donation: a cross-country study. Journal of Health Economics, 25(4), 599-620. DOI: 10.1016/j.jhealeco.2006.01.003

Abhyankar, P., Summers, B. A., Velikova, G., \& Bekker, H. L. (2014). Framing options as choice or opportunity: does the frame influence decisions?. Medical Decision Making, 34(5), 567-582.

Araña, J. E., \& León, C. J. (2013). Can defaults save the climate? Evidence from a field experiment on carbon offsetting programs. Environmental and Resource Economics, 54(4), 613-626. DOI: 10.1007/s10640-012-9615-X

Benartzi, S., \& Thaler, R. H. (1999). Risk aversion or myopia? Choices in repeated gambles and retirement investments. Management Science, 45(3), 364-381. DOI: $10.1287 / \mathrm{mnsc} .45 .3 .364$

Bohner, G., \& Schlüter, L. E. (2014). A room with a viewpoint revisited: descriptive norms and hotel guests' towel reuse behavior. PloS Oone, 9(8), e104086. DOI: 10.1371/journal.pone.0104086

Brewer, M. B., \& Kramer, R. M. (1986). Choice behavior in social dilemmas: Effects of social identity, group size, and decision framing. Journal of Personality and Social Psychology, 50, 543-549. DOI: 10.1037/0022-3514.50.3.543

Chandrashekar, S. P., Weber, J., Chan, S. Y., Cho, W. Y., Chu, T. C. C., Cheng, B. L., \& Feldman, G. )2021. (Accentuation and compatibility :Replication and extensions of 
Shafir )1993 (to rethink Choosing versus Rejecting paradigms. Judgment and Decision Making, 16(1), 36-56. DOI: 10.1037/xge0000277

Chen, J., \& Proctor, R. W. (2017). Role of accentuation in the selection/rejection task framing effect. Journal of Experimental Psychology: General, 146(4), 543. DOI:

$10.1257 / 0002828041301632$

Cronqvist, H., \& Thaler, R. H. (2004). Design choices in privatized social-security systems: Learning from the Swedish experience. American Economic Review, 94(2), 424-428. DOI: $10.1257 / 0002828041301632$

De Martino, B., Kumaran, D., Seymour, B., \& Dolan, R. J. (2006). Frames, biases, and rational decision-making in the human brain. Science, 313(5787), 684-687. https://doi.org/10.1126/science.1128356

DellaVigna, S., \& Linos, E. (2020). RCTs to Scale: Comprehensive Evidence from Two Nudge Units. Working Paper, UC Berkeley. https://doi.org/10.3386/w27594

Ebeling, F. (2013). Non-binding defaults and voluntary contributions to a public good-clean evidence from a natural field experiment. Working Paper Series in Economics No 66, University of Cologne.

English, V., Johnson, E., Sadler, B. L., \& Sadler, A. M. (2019). Is an opt-out system likely to increase organ donation? British Medical Journal, 364(8190), 1967. https://doi.org/10.1136/bmj.1967

Evans, A. M., Dillon, K. D., Goldin, G., \& Krueger, J. I. (2011). Trust and self-control: The moderating role of the default. Judgment \& Decision Making, 6(7). 
Everett, J. A., Caviola, L., Kahane, G., Savulescu, J., \& Faber, N. S. (2015). Doing good by doing nothing? The role of social norms in explaining default effects in altruistic contexts. European Journal of Social Psychology, 45(2), 230-241.

Fagley, N. S., \& Miller, P. M. (1987). The effects of decision framing on choice of risky vs certain options. Organizational Behavior and Human Decision Processes, 39(2), 264277. DOI: 10.1016/0749-5978(87)90041-0

Ferguson, C. J., \& Heene, M. (2012). A vast graveyard of undead theories: Publication bias and psychological science's aversion to the null. Perspectives on Psychological Science, 7(6), 555-561. DOI: $10.1177 / 1745691612459059$

Franco, A., Malhotra, N., \& Simonovits, G. (2014). Publication bias in the social sciences: Unlocking the file drawer. Science, 345(6203), 1502-1505. DOI: 10.1126/science. 1255484

Gamliel, E., \& Kreiner, H. (2013). Is a picture worth a thousand words? The interaction of visual display and attribute representation in attenuating framing bias. Judgment \& Decision Making, 8(4). 482-491.

Griffiths, L. (2013). Human Transplantation (Wales) Act 2013.

Halpern, D. (2015). Inside the nudge unit: How small changes can make a big difference. Random House.

Huber, V. L., Neale, M. A., \& Northcraft, G. B. (1987). Decision bias and personnel selection strategies. Organizational Behavior and Human Decision Processes, 40(1), 136-147. DOI: $10.1016 / 0749-5978(87) 90009-4$ 
Jachimowicz, J. M., Duncan, S., Weber, E. U., \& Johnson, E. J. (2019). When and why defaults influence decisions: A meta-analysis of default effects. Behavioural Public Policy, 3(2), 159-186. DOI: $10.1017 /$ bpp.2018.43

Johnson, E. J., \& Goldstein, D. (2003). Do defaults save lives?.lives? Science 302:1338-39. https://doi.org/10.1126/science.1091721

Johnson, E. J., Bellman, S., \& Lohse, G. L. (2002). Defaults, framing and privacy: Why opting in-opting out. Marketing Letters, 13(1), 5-15. DOI: 10.1023/A:1015044207315

Johnson, E. J., Hershey, J., Meszaros, J., \& Kunreuther, H. (1993). Framing, probability distortions, and insurance decisions. Journal of Risk and Uncertainty, 7(1), 35-51. DOI: 10.1007/bf01065313

Kahneman, D. (2003). Maps of bounded rationality: Psychology for behavioral economics. American Economic Review, 93(5), 1449-1475. DOI: $10.1257 / 000282803322655392$

Keller, P. A., Harlam, B., Loewenstein, G., \& Volpp, K. G. (2011). Enhanced active choice: A new method to motivate behavior change. Journal of Consumer psychology, 21(4), 376383.

Kettle, S., Hernandez, M., Sanders, M., Hauser, O., \& Ruda, S. (2017). Failure to CAPTCHA attention: Null results from an honesty priming experiment in Guatemala. Behavioral Sciences, 7(2), 28. DOI: 10.3390/bs7020028 
Kramer, R. M. (1989). Windows of vulnerability or cognitive illusions? Cognitive processes and the nuclear arms race. Journal of Experimental Social Psychology, 25, 79-100. DOI: 10.1016/0022-1031(89)90040-1

Krishnamurthy, P., Carter, P., \& Blair, E. (2001). Attribute framing and goal framing effects in health decisions. Organizational Behavior and Human Decision Processes, 85(2), 382399. DOI: $10.1006 /$ obhd.2001.2962

Kristal, A. S., Whillans, A. V., Bazerman, M. H., Gino, F., Shu, L. L., Mazar, N., \& Ariely, D. (2020). Signing at the beginning versus at the end does not decrease dishonesty. Proceedings of the National Academy of Sciences, 117(13), 7103-7107. DOI: 10.1073/pnas. 1911695117

Kruglanski, A. W., \& Gigerenzer, G. (2011). Intuitive and deliberate judgments are based on common principles. Psychological Review, 118(1), 97. DOI: 10.1037/a0020762

Kühberger, A. (1998). The influence of framing on risky decisions: A metaanalysis. Organizational Behavior and Human Decision Processes, 75(1), 23-55. DOI: 10.1006/obhd.1998.2781

Kvarven, A., Strømland, E., \& Johannesson, M. (2020). Comparing meta-analyses and preregistered multiple-laboratory replication projects. Nature Human Behaviour, 4(4), 423-434. DOI: 10.1038/s41562-020-0864-3

La Nacion. (2005). El Senado aprobó la ley del donante presunto.

LeBel, E. P., Vanpaemel, W., Cheung, I., \& Campbell, L. (2019). A brief guide to evaluate replications. Meta-Psychology, 3, 1-8. DOI: 10.15626/MP.2018.843 
Levin, I. P., \& Gaeth, G. J. (1988). How consumers are affected by the framing of attribute information before and after consuming the product. Journal of Consumer Research, 15(3), 374-378. DOI: 10.1086/209174

Li, J., \& Nikolka, T. (2016). The effect of presumed consent defaults on organ donation. CESifo DICE Report, 14(4), 90-94.

Madden, S., Collett, D., Walton, P., Empson, K., Forsythe, J., Ingham, A., Morgan, K., Murphy, P., Neuberger, J., \& Gardiner, D. (2020). The effect on consent rates for deceased organ donation in Wales after the introduction of an opt-out system. Anaesthesia, 75(9), 11461152. https://doi.org/10.1111/anae.15055

Madrian, B. C., \& Shea, D. F. (2001). The power of suggestion: Inertia in 401 (k) participation and savings behavior. The Quarterly Journal of Economics, 116(4), 1149-1187. DOI: $10.1162 / 003355301753265543$

Mintz, A., \& Redd, S. B. (2003). Framing effects in international relations. Synthese, 135(2), 193-213. DOI: 10.1111/j.1468-2478.2011.00662.x

Piñon, A., \& Gambara, H. (2005). A meta-analytic review of framing effect: risky, attribute and goal framing. Psicothema, 17(2), 325-331.

Puto, C. P. (1987). The framing of buying decisions. Journal of Consumer Research, 14(3), 301315. DOI: $10.1086 / 209115$

Reiter, P. L., McRee, A. L., Pepper, J. K., \& Brewer, N. T. (2012). Default policies and parents' consent for school-located HPV vaccination. Journal of Behavioral Medicine, 35(6), 651657. 
Rothman, A. J., \& Salovey, P. (1997). Shaping perceptions to motivate healthy behavior: the role of message framing. Psychological Bulletin, 121(1), 3. DOI: 10.1037/0033-2909.121.1.3

Schmidt, A. T., \& Engelen, B. (2020). The ethics of nudging: An overview. Philosophy Compass, 15(4), e12658. DOI: 10.1111/phc3.1265

Shafir, E., Simonson, I., \& Tversky, A. (1993). Reason-based choice. Cognition, 49(1-2), 11-36.

Shealy, T., \& Klotz, L. (2015). Well-endowed rating systems: How modified defaults can lead to more sustainable performance. Journal of Construction Engineering and Management, 141(10), 04015031.

Szaszi, B., Palinkas, A., Palfi, B., Szollosi, A., \& Aczel, B. (2018). A systematic scoping review of the choice architecture movement: Toward understanding when and why nudges work. Journal of Behavioral Decision Making, 31(3), 355-366. DOI: 10.1002/bdm.2035

Trujillo, C. (2013). Uruguay: New Law Renders all Citizens Organ Donors.

Tversky, A., \& Kahneman, D. (1981). The framing of decisions and the psychology of choice. Science, 211(4481), 453-458. DOI: 10.1126/science.7455683

Van Dalen, H. P., \& Henkens, K. (2014). Comparing the effects of defaults in organ donation systems. Social Science \& Medicine, 106, 137-142. DOI:

10.1016/j.socscimed.2014.01.052

Weber, E. U., \& Johnson, E. J. (2009). Mindful judgment and decision making. Annual Review of Psychology, 60, 53-85. DOI: 10.1146/annurev.psych.60.110707.163633

Wedell, D. H. (1997). Another look at reasons for choosing and rejecting. Memory \& Cognition, 25(6), 873-887. DOI: 10.3758/bf03211332 
Zhen, S., \& Yu, R. (2016). All framing effects are not created equal: Low convergent validity between two classic measurements of framing. Scientific Reports, 6(1), 1-9. DOI: $10.1038 /$ srep30071

Zúñiga-Fajuri, A. (2015). Increasing organ donation by presumed consent and allocation priority: Chile. Bulletin of the World Health Organization, 93(3): 199-202. DOI: 10.2471/BLT.14.139535 


\section{Default effect replications and extensions: Supplementary}

\section{Contents}

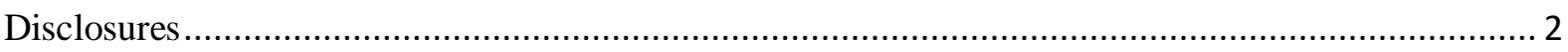

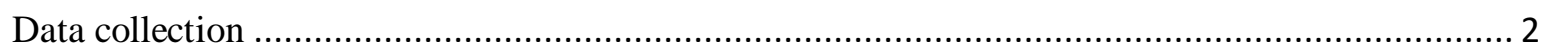

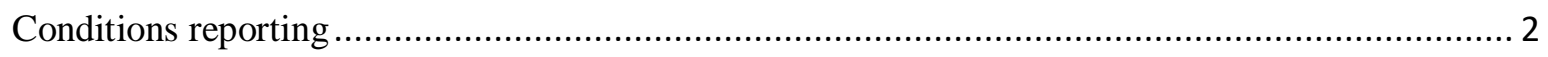

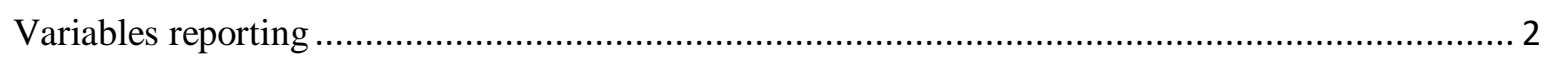

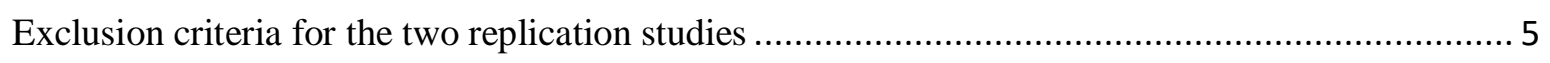

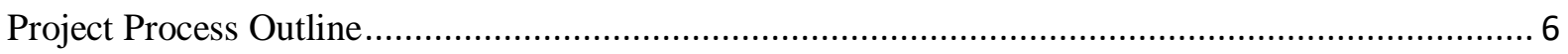

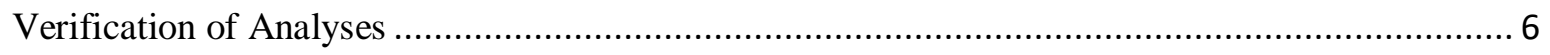

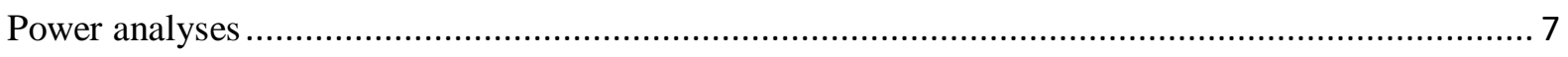

Sample comparison between the original studies and our two studies .......................................... 12

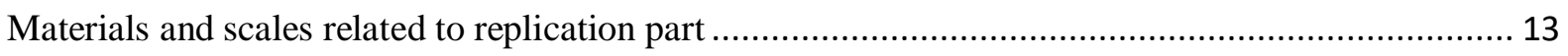

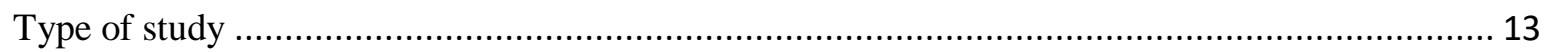

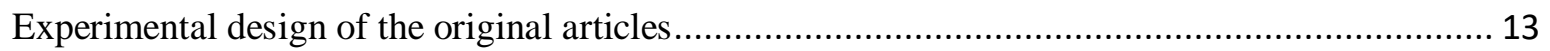

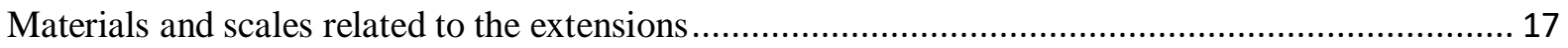

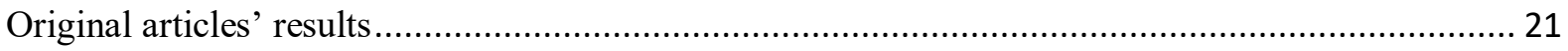

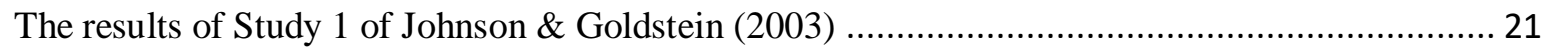

The results of Study 2 of Johnson, Bellman \& Lohse, 2002 ..................................................... 21

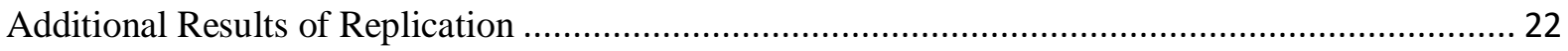

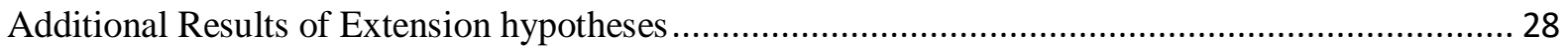

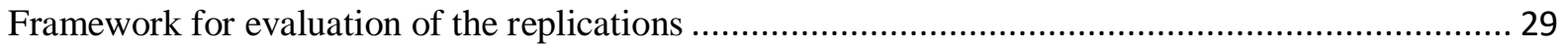

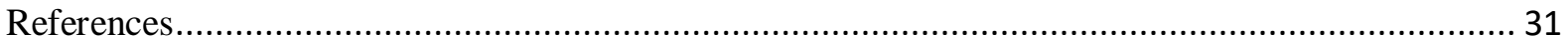




\section{Disclosures}

Data collection

Data collection was completed before analyzing the data.

Conditions reporting

We report all the conditions we collected.

Variables reporting

All variables collected for this study are reported and included in the provided data. 


\section{Author bios}

Subramanya Prasad Chandrashekar is a research assistant professor with the Lee Shau Kee School of Business and Administration at the Open University of Hong Kong. His research focuses on social status, lay-beliefs, and judgment and decision-making.

Paul Henne is an Assistant Professor of Philosophy at Lake Forest College. He is affiliated with the neuroscience program at Lake Forest College. He works on experimental philosophy.

Nadia Adelina, Shiyuan Zeng, Yan Ying Esther Chiu, and Yat Sum Leung were students at the University of Hong Kong during the academic year 2019-2020.

Boley Cheng was a teaching assistant at the University of Hong Kong psychology department during the academic year 2019-2020.

Gilad Feldman is an assistant professor with the University of Hong Kong psychology department. His research focuses on judgment and decision-making.

\section{Corresponding author}

Gilad Feldman, Department of Psychology, University of Hong Kong, Hong Kong SAR; gfeldman@hku.hk

\section{Declaration of Conflict of Interest:}

The author(s) declared no potential conflicts of interest with respect to the authorship and/or publication of this article.

\section{Financial disclosure/funding:}

Subramanya Prasad Chandrashekar would like to thank the Institute of International Business and Governance (IIBG), established with the substantial support of a grant from the Research Grants Council of the Hong Kong Special Administrative Region, China (UGC/IDS 16/17), for its support. 


\section{Authorship declaration:}

Table S0. Authors' contribution

In the Table below, we employ CRediT (Contributor Roles Taxonomy) to identify the contribution and roles played by the contributors in the current replication effort. Please refer to the URL (https://www.casrai.org/credit.html ) on details and definitions of each of the roles listed below.

\begin{tabular}{|c|c|c|c|c|c|}
\hline Role & Prasad & Paul & $\begin{array}{c}\text { Nadia Adelina, } \\
\text { Shiyuan Zeng, Yan } \\
\text { Ying Esther Chiu, Yat } \\
\text { Sum Leung } \\
\end{array}$ & $\begin{array}{l}\text { Boley } \\
\text { Cheng }\end{array}$ & $\begin{array}{c}\text { Gilad } \\
\text { Feldman }\end{array}$ \\
\hline Conceptualization & & & $X$ & & $X$ \\
\hline Pre-registration & & & $X$ & & $\mathrm{X}$ \\
\hline Data curation & & & & & $\mathrm{X}$ \\
\hline Formal analysis & $\mathrm{X}$ & $\mathrm{X}$ & $\mathrm{X}$ & & \\
\hline Funding acquisition & & & & & $X$ \\
\hline Investigation & $\mathrm{X}$ & $\mathrm{X}$ & $\mathrm{X}$ & & $X$ \\
\hline Methodology & & & $X$ & & $X$ \\
\hline $\begin{array}{l}\text { Pre-registration peer review / } \\
\text { verification }\end{array}$ & $X$ & & $X$ & $X$ & $X$ \\
\hline $\begin{array}{l}\text { Data analysis peer } \\
\text { review/verification }\end{array}$ & $\mathrm{X}$ & & $X$ & & \\
\hline Project administration & & & & $X$ & $X$ \\
\hline Resources & & & & & $X$ \\
\hline Software & $\mathrm{X}$ & $\mathrm{X}$ & $\mathrm{X}$ & & \\
\hline Supervision & & & & $\mathrm{X}$ & $X$ \\
\hline Validation & $\mathrm{X}$ & $\mathrm{X}$ & & & \\
\hline Visualization & $\mathrm{X}$ & $\mathrm{X}$ & & & \\
\hline Writing-original draft & $\mathrm{X}$ & $\mathrm{X}$ & & & \\
\hline Writing-review and editing & $X$ & $\mathrm{X}$ & & & $\mathrm{X}$ \\
\hline
\end{tabular}




\section{Exclusion criteria for the two replication studies}

1. Subjects indicating a low proficiency of English (self-report < 5, on a 1-7 scale);

2. Subjects who self-report not being serious about filling in the survey (self-report < 4 , on a $1-5$ scale);

3. Subjects who correctly guessed the hypothesis of this study in the funnelling section;

4. Have seen or done the survey before;

5. Subjects who failed to complete the survey. (duration $=0$, leave question blank);

6. Not from the United States; 


\section{Project Process Outline}

The current replication is part of the mass pre-registered replication project, with the primary aim of revisiting well-known research findings in the area of judgment and decision making (JDM) and examining the reproducibility and replicability of these findings. The current replication study followed the same project outline as noted below. For each of the replication projects, researchers completed full pre-registrations, data analysis, and APA style submission-ready reports. The authors independently reproduced the materials and designed the replication experiment, with a separate pre-registration document. The researchers then peer-reviewed one another to try and arrive at the best possible design. Then, the lead and corresponding authors reviewed the integrated work and the last corresponding author made final adjustments and conducted the pre-registration and data collection. The OSF page of the project contains the Qualtrics survey design used for data collection with pre-registration documents submitted by each of the researchers. In the manuscript, we followed the most conservative of the pre-registrations.

Figure S1. Project process diagram

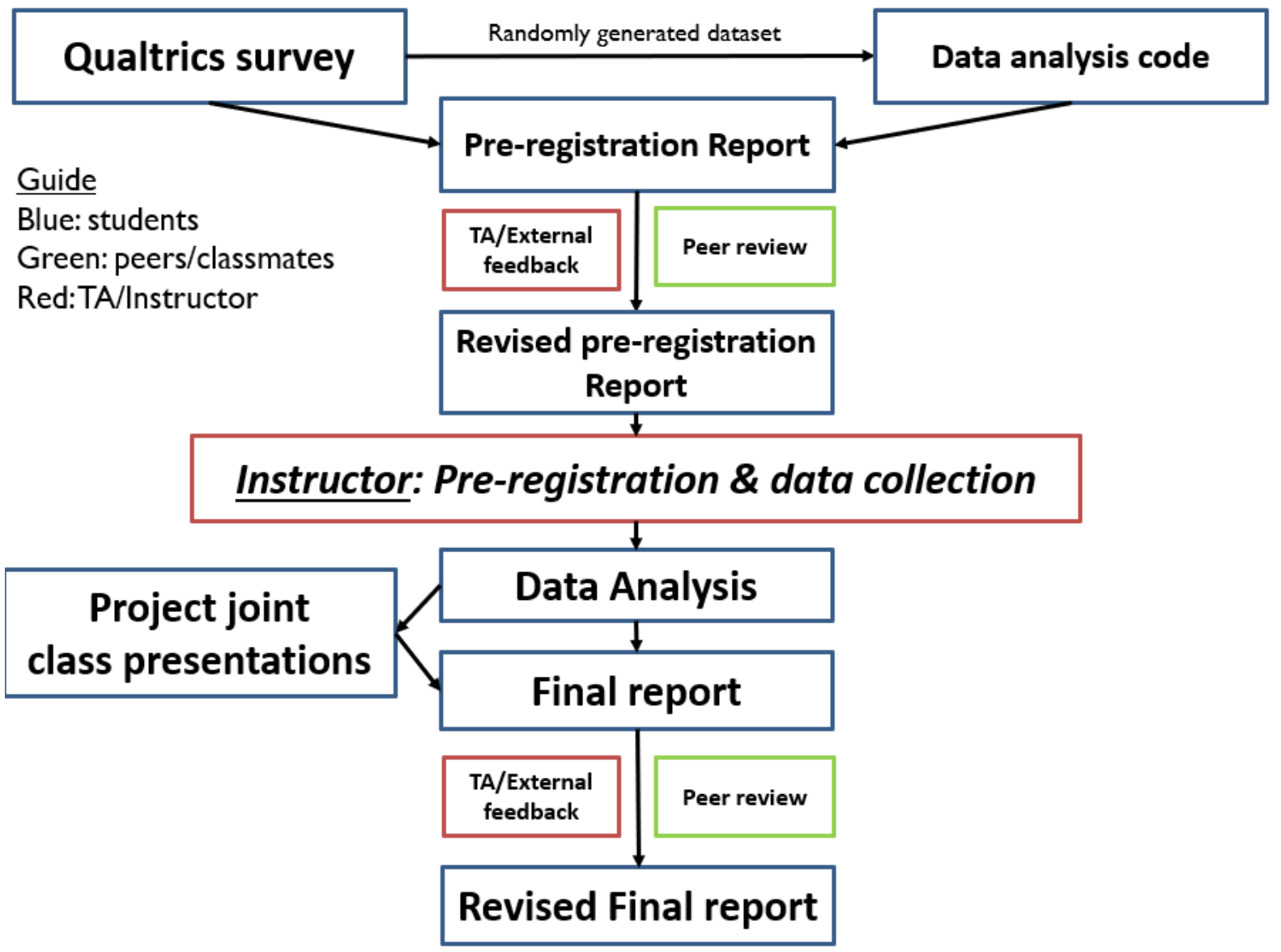


Initial analyses were conducted by the independent researchers, who used JAMOVI (jamovi project, 2018) or $\mathrm{R}$ for data analyses. In preparing this manuscript, the lead and corresponding authors verified the analyses in $\mathrm{R}$.

\section{Power analyses}

The rationale for reconstructing the original dataset and re-running logistic regression: authors of the original studies did not report full statistical results necessary for calculating effect size and power analysis. Hence, we had to re-conduct the test based on the data (consent rates/participation rates in different experimental conditions) available in the original paper. Given the study, designs involved binary outcome variables frequency tables and figures noted in the original papers allowed us to reconstruct accurate data collected during the original studies.

\section{Steps for power analysis (Johnson \& Goldstein, 2003):}

1. Conducted Binomial Logistic Regression in Jamovi based on the reconstructed data file ("OrigOrganDonation.csv" available on the OSF page of the project).

2. We calculated the Odds Ratios of the Binomial Logistic Regression results in Jamovi.

3. Used the odds ratio for the power analysis with GPower (Faul et al., 2007).

\section{Supplementary screenshots}

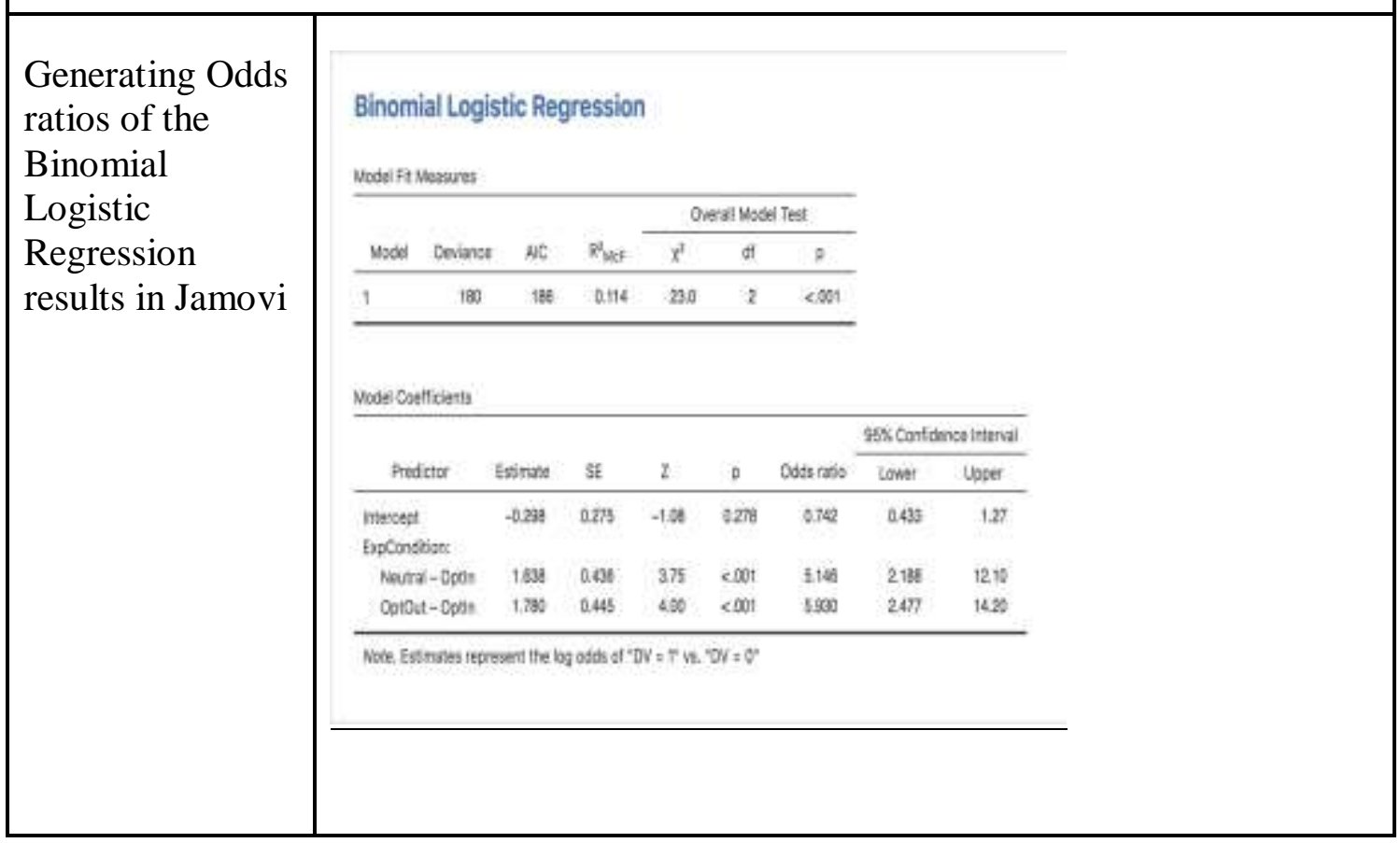




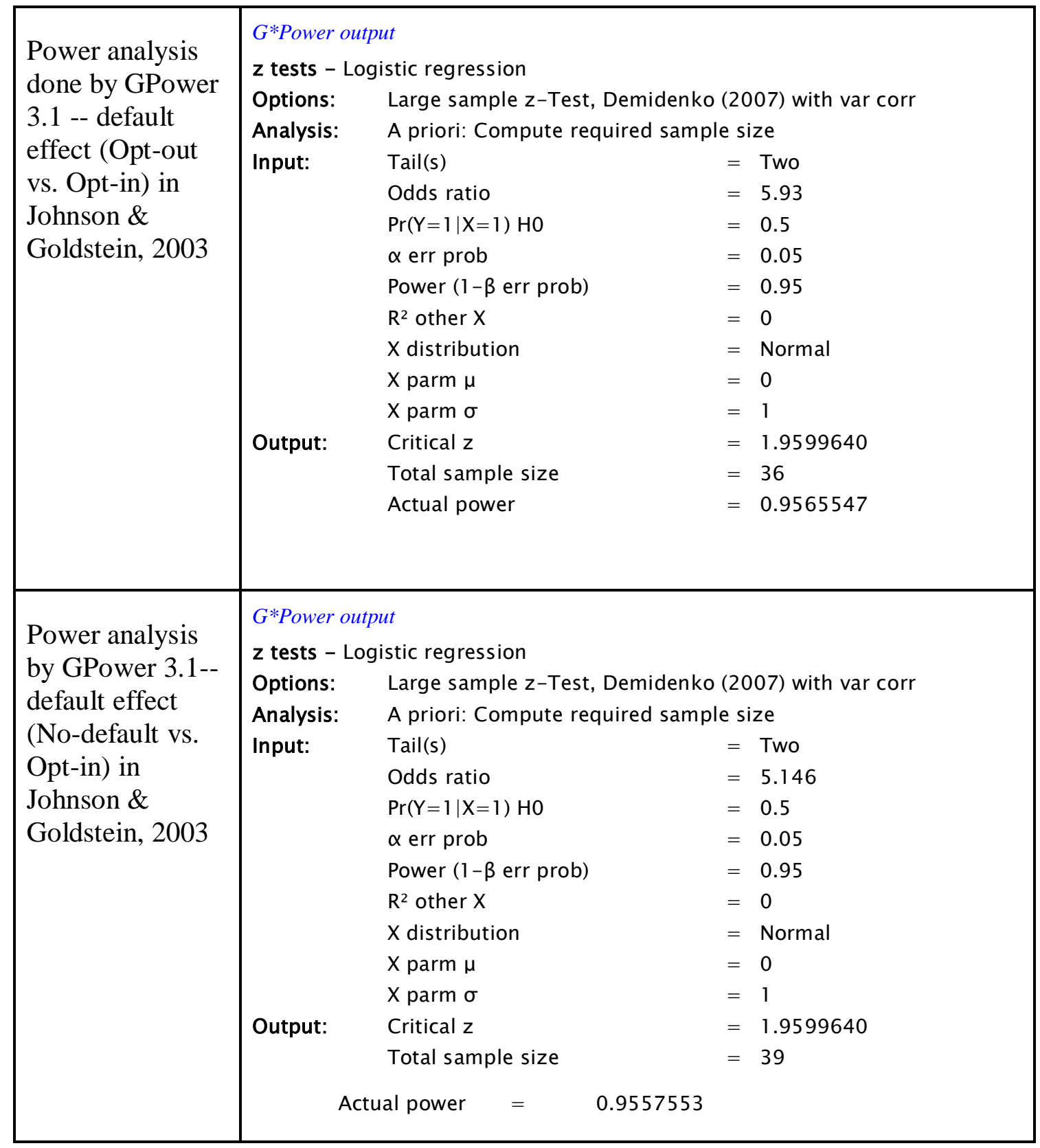




\section{Steps for power analysis (Johnson, Bellman \& Lohse, 2002):}

1. Conducted a Binomial Logistic Regression analysis in Jamovi based on the reconstructed data file ("OrigHealthSurvey.csv" available on the OSF page of the project).

2. Used the odds ratio from Jamovi output for the power analysis with GPower.

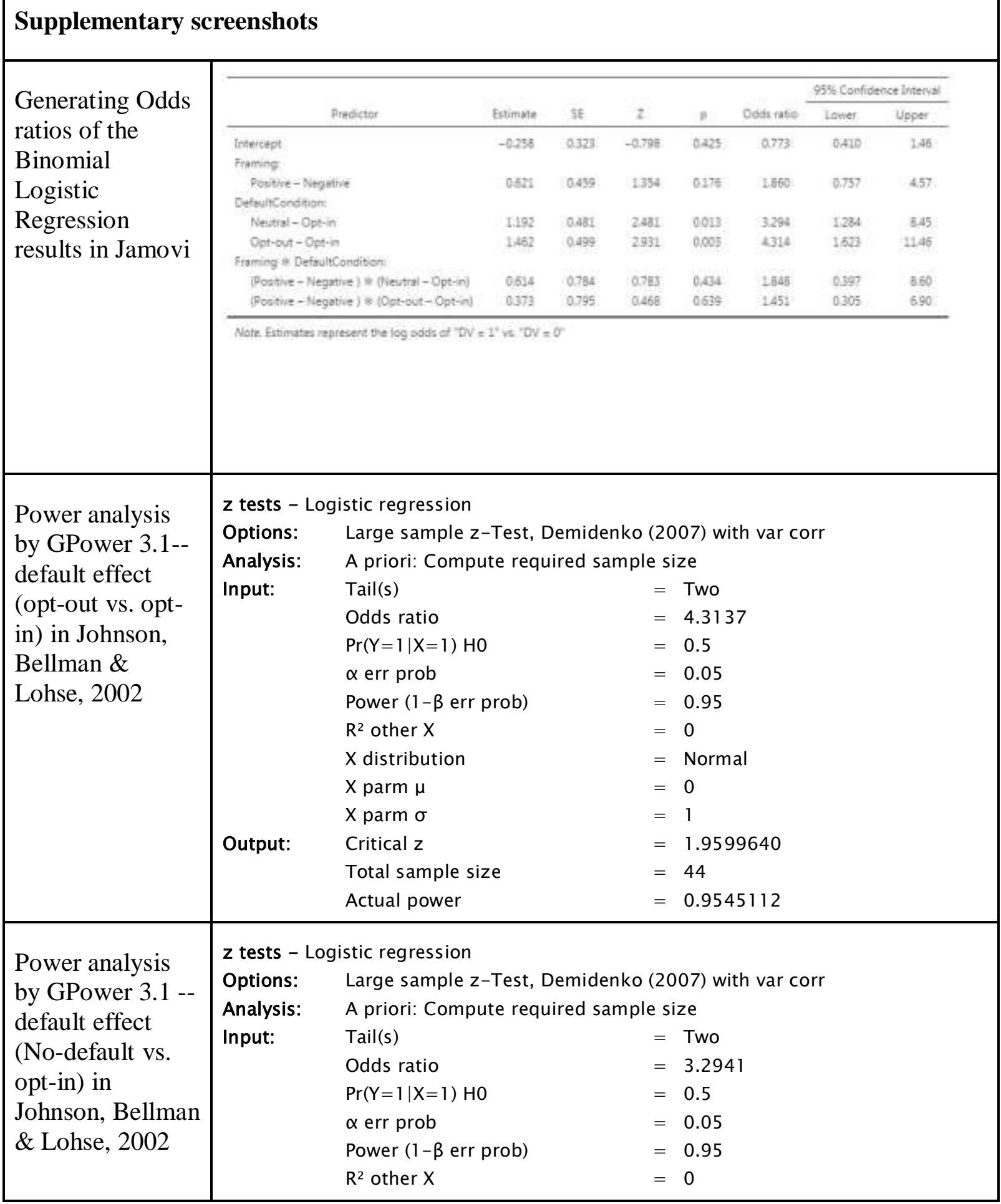




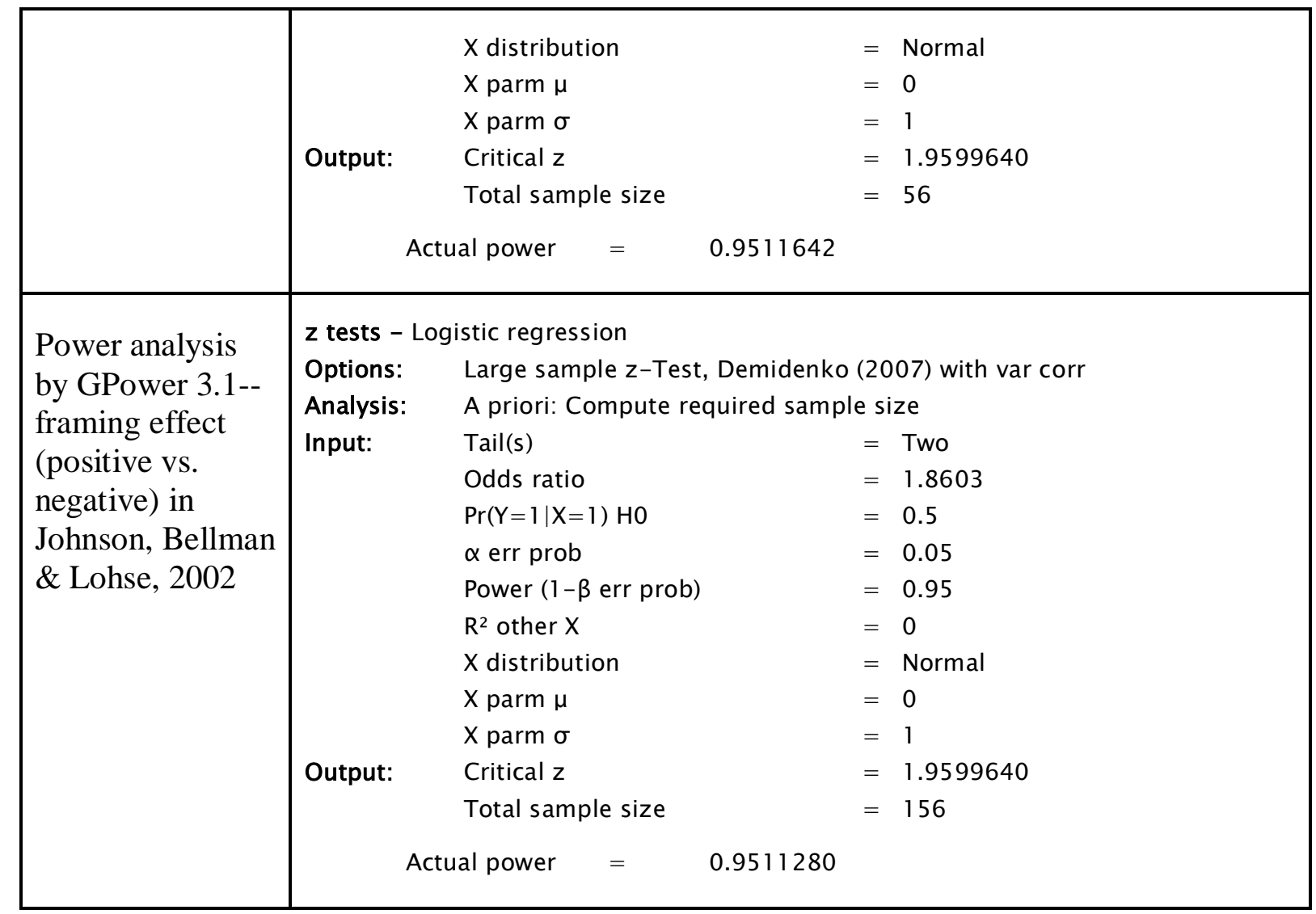

Table S1. Summary of power analysis for the original paper:

\begin{tabular}{|c|c|c|c|c|}
\hline $\begin{array}{l}\text { Original } \\
\text { Article }\end{array}$ & Effect & Conditions & $\begin{array}{l}\text { Calculated } \\
\text { Sample Size }\end{array}$ & $\begin{array}{l}\text { Actual } \\
\text { Power }\end{array}$ \\
\hline \multirow{2}{*}{$\begin{array}{l}\text { Johnson \& } \\
\text { Goldstein } \\
(2003)\end{array}$} & \multirow{2}{*}{ Default Effect } & Opt-out - Opt-in & 36 & 0.95 \\
\hline & & No-default - Opt-in & 39 & 0.95 \\
\hline \multirow{3}{*}{$\begin{array}{l}\text { Johnson, } \\
\text { Bellman \& } \\
\text { Lohse (2002) }\end{array}$} & \multirow{2}{*}{ Default Effect } & Opt-out - Opt-in & 44 & 0.95 \\
\hline & & No-default - Opt-in & 56 & 0.95 \\
\hline & Framing Effect & Negative - Positive & 156 & 0.95 \\
\hline \multicolumn{3}{|c|}{ Total required sample size } & \multicolumn{2}{|l|}{$\sim 156$ or more } \\
\hline
\end{tabular}

Notes: We choose a sufficiently larger sample size to ensure sufficient power of $95 \%$ to detect effects noted in the target studies and the effects of the proposed extension hypothesis that included six between-subjects conditions (conceptual replication of Johnson et al., 2002). 


\section{Power sensitivity analyses}

Power sensitivity analysis based on the final sample (i.e., Sample $1=954)$ indicate that the final sample has $80 \%$ power (at $\alpha=.05$ ) detect an small-medium effect size (Odds Ratio = 1.54).

\section{Power sensitivity analysis output using GPower 3.1:}
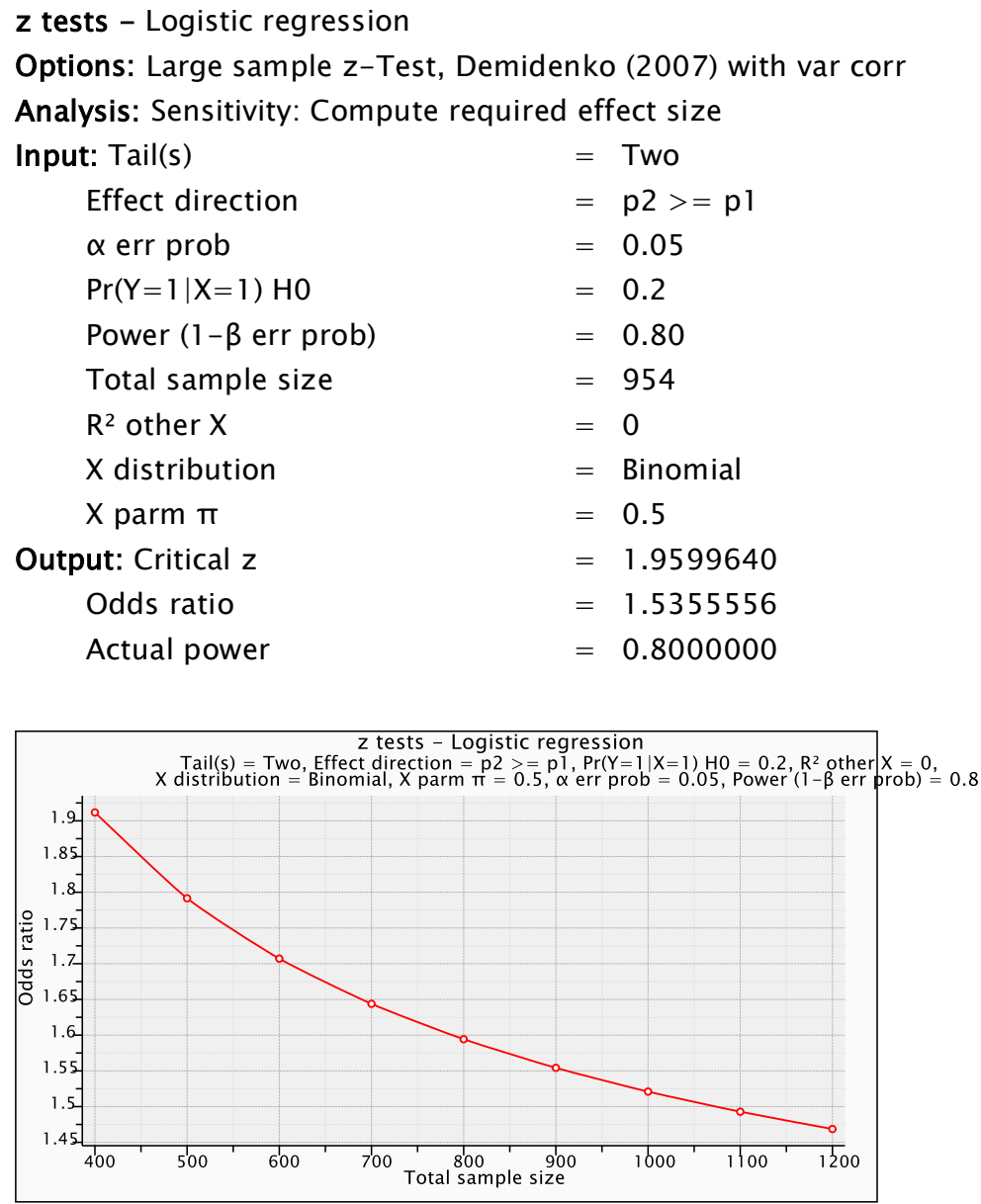


\section{Sample comparison between the original studies and our two studies}

Table S2. Sample differences and similarities between the original studies and our replication samples

\begin{tabular}{lllll}
\hline & $\begin{array}{l}\text { Johnson \& } \\
\text { Goldstein }(2003)\end{array}$ & $\begin{array}{l}\text { Johnson, Bellman } \\
\text { \& Lohse (2002) }\end{array}$ & $\begin{array}{l}\text { Sample 1: } \\
\text { American } \\
\text { MTurk workers }\end{array}$ & $\begin{array}{l}\text { Sample 2: } \\
\text { American } \\
\text { MTurk workers }\end{array}$ \\
\hline Sample size & 161 & 235 & $954^{*}$ & 966 \\
Geographic origin & International & International & US Americans & US Americans \\
Gender & Not reported & $\begin{array}{l}124 \text { males, 153 } \\
\text { females }\end{array}$ & $\begin{array}{l}459 \text { males, 495 } \\
\text { females }\end{array}$ & $\begin{array}{l}459 \text { males, 514 } \\
\text { females }\end{array}$ \\
Average age (years) & Not reported & 35.4 & 38.7 & 39.2 \\
Age range (years) & Not reported & Not reported & $19-76$ & $19-76$ \\
Medium (location) & $\begin{array}{l}\text { Computer } \\
\text { (online) }\end{array}$ & $\begin{array}{l}\text { Computer } \\
\text { (online) }\end{array}$ & $\begin{array}{l}\text { Computer } \\
\text { (online) }\end{array}$ & $\begin{array}{l}\text { Computer } \\
\text { (online) }\end{array}$ \\
Compensation & $\$ 4.00$ & Not reported & $\begin{array}{l}\text { Nominal } \\
\text { payment }\end{array}$ & $\begin{array}{l}\text { Nominal } \\
\text { payment }\end{array}$ \\
Year & 2003 & 2002 & $\begin{array}{l}2019 \\
2019\end{array}$ \\
\hline
\end{tabular}

Differences and similarities between participant sample in the original study and replication.

Note: (*) 480 out of 954 participants in the Mturk sample were assigned to conditions that aimed to replicate the original findings. The remaining 474 participants were assigned to experimental conditions designed as part of the extension. 


\section{Materials and scales related to replication part}

\section{Type of study}

Johnson \& Goldstein, 2003: Between subjects design

Johnson, Bellman \& Lohse, 2002: Experimental Manipulations (Mixed design).

\section{Experimental design of the original articles}

Participants were asked to imagine that they have just moved to a new state and that they are filling out paperwork related to their move. The instruction that noted that they are "filling out the required online registration forms" upon their arrival at the new state, which was not present in Johnson \& Goldstein (2003). This addition aimed to make the transition from the organ donor form (Part 1) to the health survey (Part 2) related forms more coherent.

\section{Johnson \& Goldstein, 2003}

Three studies were reported in Johnson and Goldstein's (2003) work to evaluate the effect of the default on the agreement rate of organ donations. The focus of the current replication study is on the first experiment, which investigates the effect of three default conditions (i.e. opt-out, opt-in and no-default condition) on organ donation rate through the format of an online survey. Experiment 1 from the original research used a 3 (default options) between-subject design. The respondents of an online experiment were assigned to one of the three conditions with different default options. Participants were asked whether they would be donors based on one of the three questions with varying defaults. Table 7 shows the three experimental conditions.

Table S3. Experimental Design of Johnson \& Goldstein, 2003 and our replication studies

\section{Default Effect (Johnson \& Goldstein, 2003)}

Participants were told to complete an online survey, in the survey, they were told to assume that they have just moved to a new state and were asked whether they would be donors based on one of the three questions with varying defaults. Participants were randomly assigned to answer 1 out of 3 different default conditions of the question.

\begin{tabular}{|c|c|c|c|}
\hline Independent & IV condition 1: & IV condition $2:$ & IV condition $3:$ \\
\hline Variable: & Opt-out condition & Opt-in condition & No-default (no \\
\hline Default & & & default) condition \\
\hline (between subjects) & $\begin{array}{l}\text { Participants answered } \\
\text { the following multiple- } \\
\text { choice question: }\end{array}$ & $\begin{array}{l}\text { Participants answered } \\
\text { the following multiple- } \\
\text { choice question: }\end{array}$ & $\begin{array}{l}\text { Participants answered } \\
\text { the following multiple- } \\
\text { choice question: }\end{array}$ \\
\hline
\end{tabular}




\begin{tabular}{|c|c|c|c|}
\hline & $\begin{array}{l}\text { Assume you moved to a } \\
\text { new state in which the } \\
\text { default is that you are } \\
\text { an organ donor, you are } \\
\text { therefore by default } \\
\text { enrolled as an organ } \\
\text { donor. Please choose } \\
\text { your preferred organ } \\
\text { donor status: } \\
\text { Participants were given } \\
\text { two options: } \\
\text { - YES - Organ } \\
\quad \text { donor } \\
\text { - NO - Not organ } \\
\quad \text { donor } \\
\text { The option "YES - } \\
\text { Organ donor" was set } \\
\text { as the default option. }\end{array}$ & $\begin{array}{l}\text { Assume you moved to a } \\
\text { new state in which the } \\
\text { default is that you are } \\
\text { not an organ donor, you } \\
\text { are therefore by default } \\
\text { not enrolled as an } \\
\text { organ donor. Please } \\
\text { choose your preferred } \\
\text { organ donor status: } \\
\text { Participants were given } \\
\text { two options: } \\
\text { - YES - Organ } \\
\quad \text { donor } \\
\text { - NO - Not organ } \\
\quad \text { donor } \\
\text { The option "NO - Not } \\
\text { organ donor" was set as } \\
\text { the default option. }\end{array}$ & $\begin{array}{l}\text { Assume you moved to a } \\
\text { new state, therefore, } \\
\text { you need to select } \\
\text { enrollment as an organ } \\
\text { donor. Please choose } \\
\text { your preferred organ } \\
\text { donor status. } \\
\text { Participants were given } \\
\text { two options: } \\
\quad \text { YES - Organ } \\
\quad \text { donor } \\
\text { NO - Not organ } \\
\quad \text { donor }\end{array}$ \\
\hline $\begin{array}{l}\text { Dependent Variable: } \\
\text { Donation agreement } \\
\text { rate }\end{array}$ & \multicolumn{3}{|c|}{$\begin{array}{l}\text { Scoring the DV: } \\
\text { Two choices were given in the multiple-choice questions, which were coded } \\
\text { with numerical values for further calculation: } \\
\text { - } Y E S \text { - Organ donor }=1 \\
\text { - NO - Not organ donor }=0 \\
\text { Value ' } 1 \text { ' indicated consent for organ donation, whereas, ' } 0 \text { ' indicated } \\
\text { disagreeing to donate the organs. }\end{array}$} \\
\hline
\end{tabular}




\section{Johnson, Bellman \& Lohse, 2002}

Experiment 2 of Johnson, Bellman \& Lohse, 2002 employed a 2(framing) x 3(default) between-subject design, wherein each respondent of an online health survey was randomly assigned to answer one of six variations of the same question at the end of the survey they just completed. The dependent variable essentially asked whether the respondent would like to be contacted in the future for opportunities to participate in more health surveys. Table 1 details the six experimental conditions.

Table S4. . Experimental Design of Experiment 2 in Johnson, Bellman \& Lohse, 2002 and our replication studies

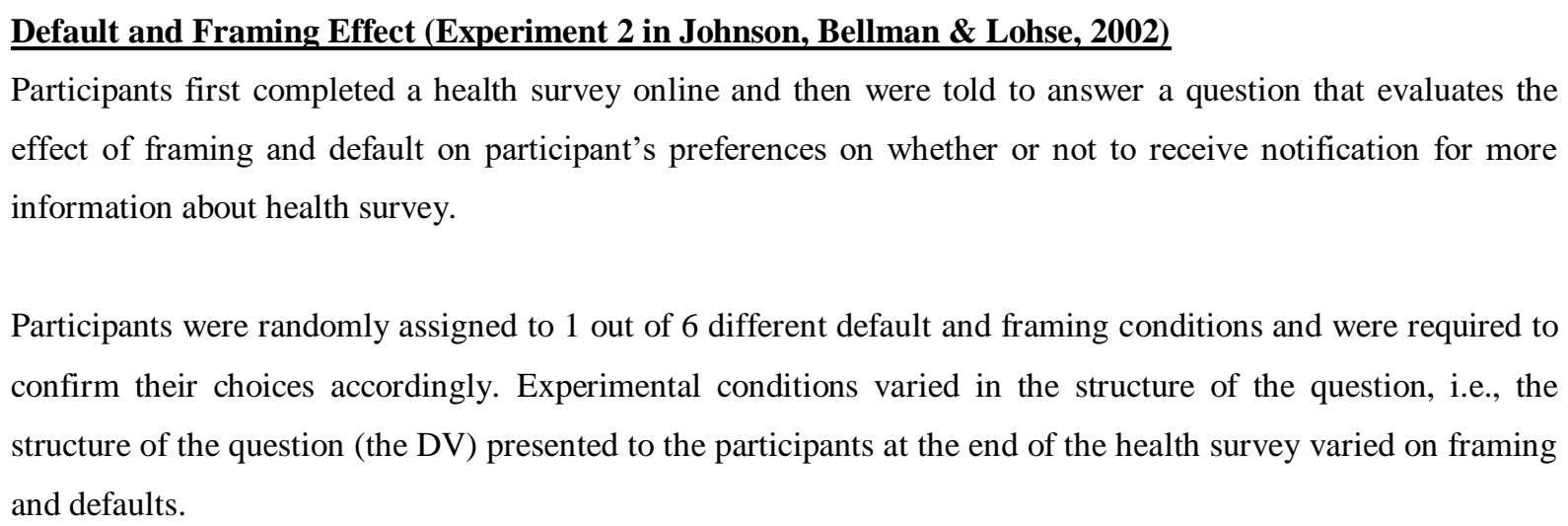

Participants were randomly assigned to 1 out of 6 different default and framing conditions and were required to confirm their choices accordingly. Experimental conditions varied in the structure of the question, i.e., the structure of the question (the DV) presented to the participants at the end of the health survey varied on framing and defaults.

\begin{tabular}{|c|c|c|c|c|}
\hline $\begin{array}{l}\text { Independent Variable: } \\
\text { Framing } \\
\text { (between subjects) }\end{array}$ & \multicolumn{2}{|c|}{$\begin{array}{l}\text { IV condition 1: } \\
\text { Positive framing condition } \\
\text { The following statement was randomly } \\
\text { assigned to the participants : }\end{array}$} & \multicolumn{2}{|c|}{$\begin{array}{l}\text { The following statement was randomly } \\
\text { assigned to the participants : }\end{array}$} \\
\hline $\begin{array}{l}\text { Independent Variable: } \\
\text { Default } \\
\text { (between subjects) }\end{array}$ & $\begin{array}{l}\text { IV condition } 1 \text { : } \\
\text { Opt-out condition } \\
\text { Default option: Yes }\end{array}$ & \multicolumn{2}{|c|}{$\begin{array}{l}\text { IV condition } 2 \text { : } \\
\text { Opt-in condition } \\
\text { Default option: No }\end{array}$} & $\begin{array}{l}\text { IV condition } 3 \text { : } \\
\text { No default condition } \\
\text { No default option was } \\
\text { given. }\end{array}$ \\
\hline Dependent Variable & $\begin{array}{l}\text { DV item variations } \mathrm{i} \\
\text { Participants were rec } \\
\text { whether or not to rec } \\
\text { about more health su }\end{array}$ & $\begin{array}{l}\text { Ing: } \\
\text { o choose } \\
\text { tification }\end{array}$ & $\begin{array}{l}\text { DV } \\
\text { Parti } \\
\text { whet } \\
\text { abou }\end{array}$ & $\begin{array}{l}\text { lations in default: } \\
\text { were required to choose } \\
\text { ot to receive notification } \\
\text { ealth surveys. }\end{array}$ \\
\hline
\end{tabular}




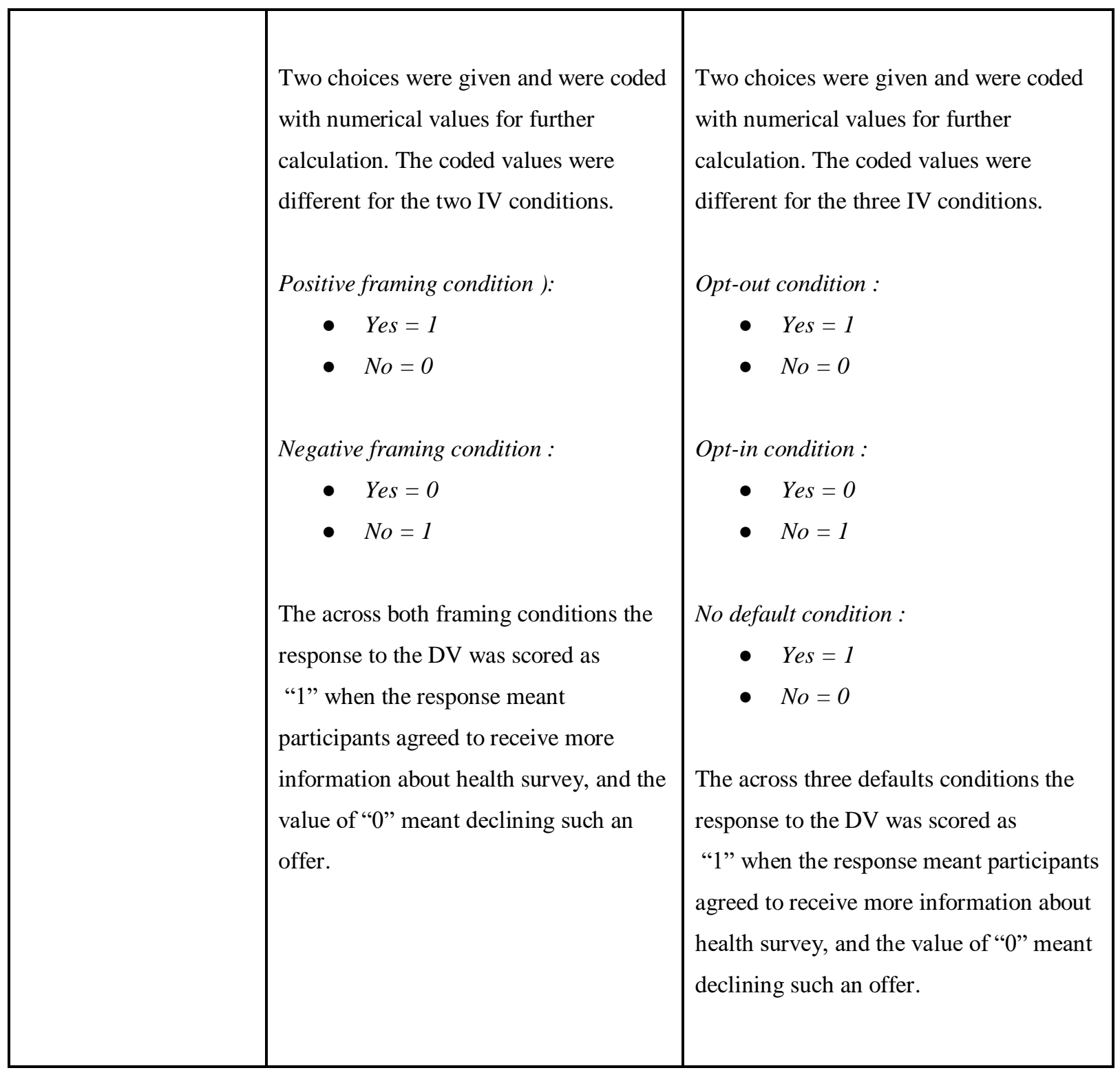




\section{Materials and scales related to the extensions}

Table S5. Experimental design of Extension 1: Organ donation scenario (Permanent vs. Temporary)

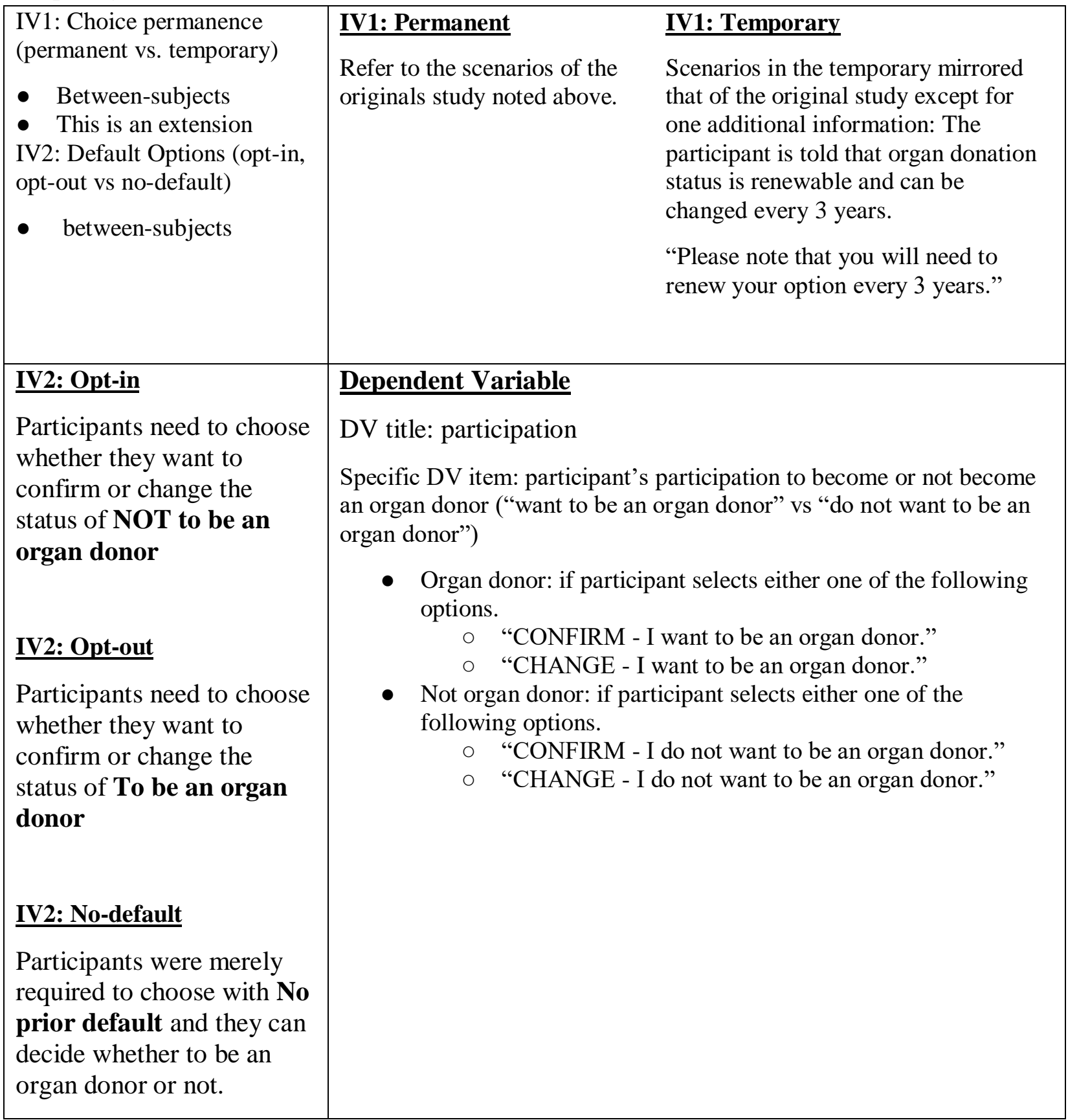

Note: The extension was part of the Sample 1 data collection

Extension 2: Conceptual replication of Johnson et al. (2002). 
Extension 2 mirrored the Experiment 2 of Johnson, Bellman \& Lohse, 2002 : a 2 (framing) x 3(default) between-subject design, wherein each respondent answer one of six variations of the same questions. The dependent variable essentially asked whether the respondent would like to receive further information on organ donation.

Table S6. Experimental design of Extension 2

\section{Extension 2: Default and Framing Effect:}

They were manipulated by changing the format of the statement with default and framing conditions. Participants were randomly assigned to 1 out of 6 different versions of the statements, and were required to confirm their choices accordingly.

\begin{tabular}{|c|c|c|c|}
\hline $\begin{array}{l}\text { Independent } \\
\text { Variable } 1 \\
\text { (IV1): Default }\end{array}$ & $\begin{array}{l}\text { IV1 condition 1: } \\
\text { Opt-out condition }\end{array}$ & $\begin{array}{l}\text { IV1 condition 2: } \\
\text { Opt-in condition }\end{array}$ & $\begin{array}{l}\text { IV1 condition } 3 \text { : } \\
\text { No default condition }\end{array}$ \\
\hline $\begin{array}{l}\text { Independent } \\
\text { Variable } 2 \\
\text { (IV2): } \\
\text { Framing }\end{array}$ & $\begin{array}{l}\text { IV2 condition 1: } \\
\text { Positive framing condition }\end{array}$ & $\begin{array}{l}\text { IV2 condition 2: } \\
\text { Negative framing cond }\end{array}$ & tion \\
\hline $\begin{array}{l}\text { Versions of } \\
\text { questions } \\
\text { formats } \\
\text { (randomly } \\
\text { assigned to } \\
\text { participants in } \\
\text { Qualtrics } \\
\text { survey) }\end{array}$ & $\begin{array}{l}\text { Version 1: Opt-in \& } \\
\text { Negative framing } \\
\text { 1. Default condition: Opt- } \\
\text { in } \\
\text { - Default option = YES } \\
\text { 2. Framing condition: } \\
\text { Negative framing } \\
\text { - The following statement } \\
\text { was randomly assigned } \\
\text { to the participants : "Do } \\
\text { NOT send me more } \\
\text { information about organ } \\
\text { donation" }\end{array}$ & $\begin{array}{l}\text { Version 2: No default } \\
\text { \& Negative framing } \\
\text { 1. Default condition: } \\
\text { No default } \\
\text { - No default option } \\
\text { was given } \\
\text { 2. Framing condition: } \\
\text { Negative framing } \\
\text { - The following } \\
\text { statement was } \\
\text { randomly assigned } \\
\text { to the participants : } \\
\text { "Do NOT send me } \\
\text { more information } \\
\text { about organ } \\
\text { donation" }\end{array}$ & $\begin{array}{l}\text { Version 3: Opt-out \& } \\
\text { Negative framing } \\
\text { 1. Default condition: } \\
\text { Opt-out } \\
\text { - Default option = } \\
\text { NO } \\
\text { 2. Framing condition: } \\
\text { Negative framing } \\
\text { - The following } \\
\text { statement was } \\
\text { randomly assigned } \\
\text { to the participants : } \\
\text { "Do NOT send me } \\
\text { more information } \\
\text { about organ } \\
\text { donation" }\end{array}$ \\
\hline
\end{tabular}




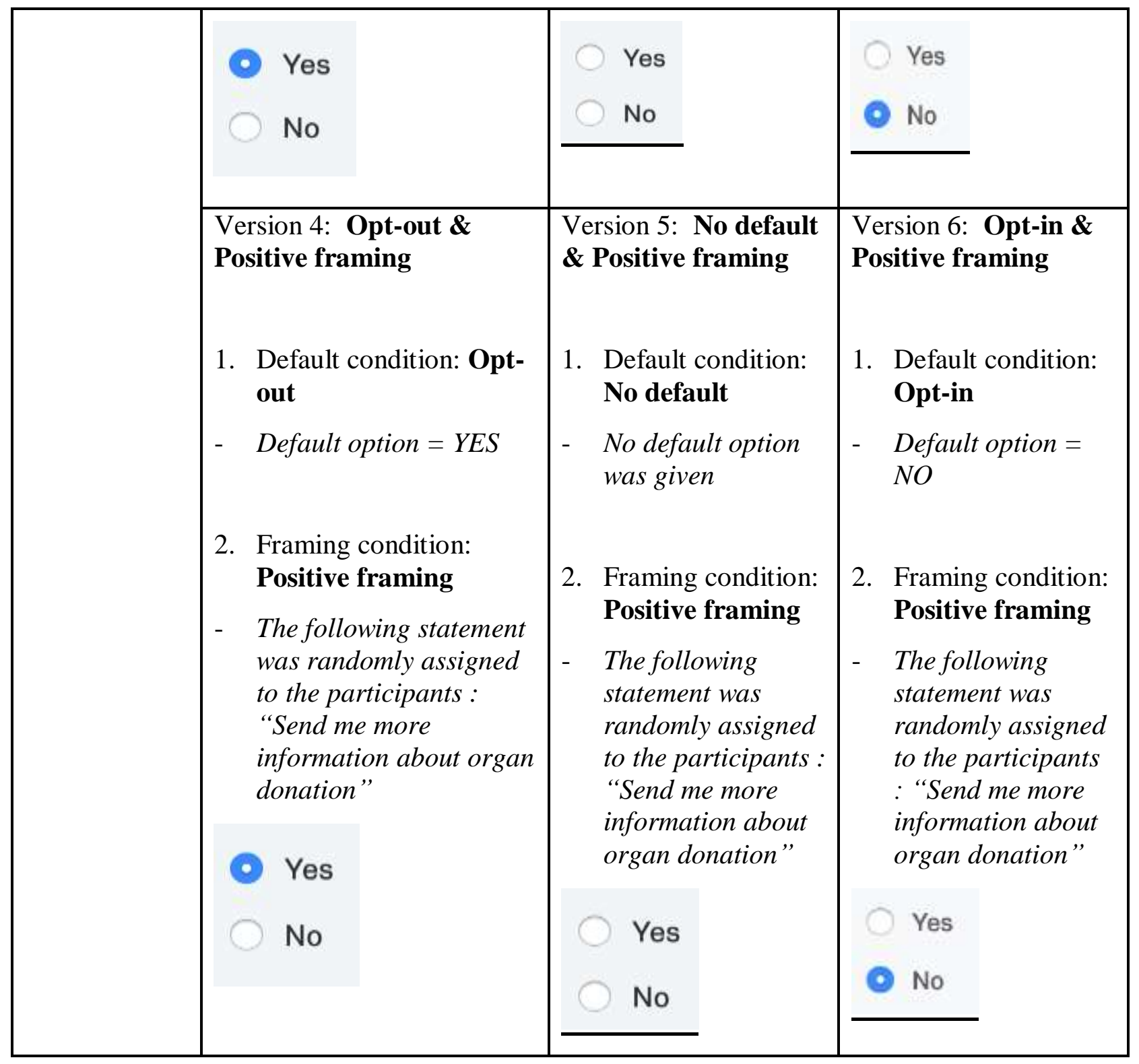




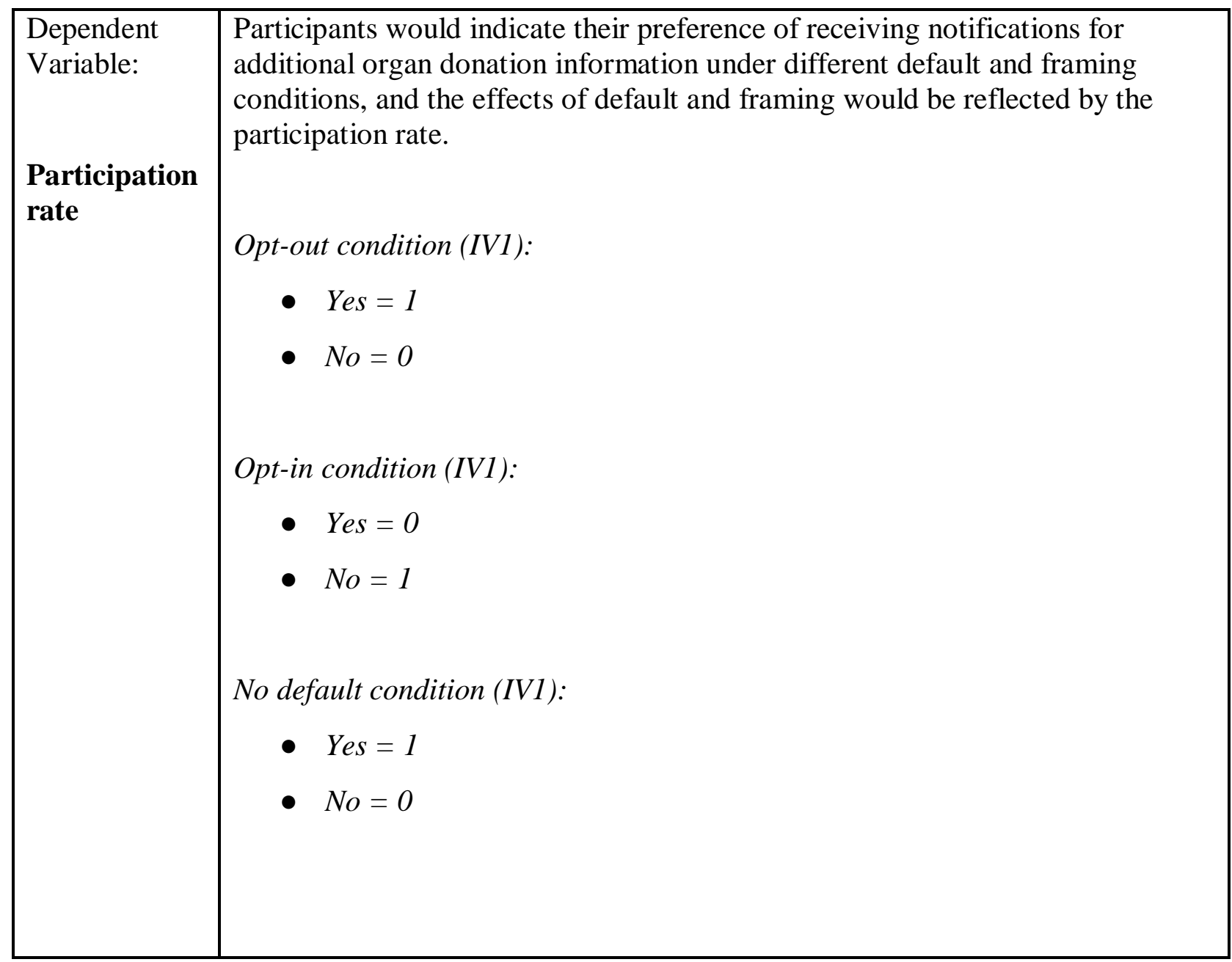




\section{Original articles' results}

We reproduced the results of the original study to help us accurately pin-point the effect sizes for the current replication and to ascertain the degree of reproducibility.

The results of Study 1 of Johnson \& Goldstein (2003)

Table S7. The results of Binomial Logistic Regression

95\% Confidence Interval

\begin{tabular}{|c|c|c|c|c|c|c|c|}
\hline \multirow[b]{2}{*}{ Predictor } & \multirow[b]{2}{*}{ Estimate } & \multirow[b]{2}{*}{ SE } & \multirow[b]{2}{*}{$\mathbf{Z}$} & \multirow[b]{2}{*}{$\mathbf{p}$} & \multirow[b]{2}{*}{ Odds ratio } & & \multirow{2}{*}{ Upper } \\
\hline & & & & & & Lower & \\
\hline Intercept & -0.298 & 0.275 & -1.08 & 0.278 & 0.742 & 0.433 & 1.27 \\
\hline \multicolumn{8}{|l|}{ Conditions: } \\
\hline No-default vs. Opt-In & 1.638 & 0.436 & 3.75 & $<.001$ & 5.146 & 2.188 & 12.10 \\
\hline Opt-Out vs. Opt-In & 1.780 & 0.445 & 4.00 & $<.001$ & 5.930 & 2.477 & 14.20 \\
\hline
\end{tabular}

Note. $\mathrm{N}=161$; Estimates represent the $\log$ odds of "DV =1" vs. "DV =0";

The results of Study 2 of Johnson, Bellman \& Lohse, 2002

Table S8. The results of Binomial Logistic Regression

\begin{tabular}{|c|c|c|c|c|c|c|c|}
\hline \multirow[b]{2}{*}{ Predictor } & \multirow[b]{2}{*}{ Estimate } & \multirow[b]{2}{*}{ SE } & \multirow[b]{2}{*}{$\mathbf{Z}$} & \multirow[b]{2}{*}{$\mathbf{p}$} & \multirow[b]{2}{*}{ Odds ratio } & \multicolumn{2}{|c|}{$\begin{array}{l}\text { 95\% Confidence } \\
\text { Interval }\end{array}$} \\
\hline & & & & & & Lower & Upper \\
\hline Intercept & -0.258 & 0.323 & $0.798^{-}$ & 0.425 & 0.773 & 0.410 & 1.46 \\
\hline \multicolumn{8}{|l|}{ Framing: } \\
\hline Positive vs. Negative & 0.621 & 0.459 & 1.354 & 0.176 & 1.860 & 0.757 & 4.57 \\
\hline \multicolumn{8}{|l|}{ Default Condition: } \\
\hline No-default vs. Opt-in & 1.192 & 0.481 & 2.481 & 0.013 & 3.294 & 1.284 & 8.45 \\
\hline Opt-out - Opt-in & 1.462 & 0.499 & 2.931 & 0.003 & 4.314 & 1.623 & 11.46 \\
\hline \multicolumn{8}{|l|}{ Framing $*$ Default Condition: } \\
\hline $\begin{array}{l}\text { (Positive vs. Negative ) } * \text { (No- } \\
\text { default vs. Opt-in) }\end{array}$ & 0.614 & 0.784 & 0.783 & 0.434 & 1.848 & 0.397 & 8.60 \\
\hline $\begin{array}{l}\text { (Positive vs. Negative }) *(\text { Opt- } \\
\text { out vs. Opt-in) }\end{array}$ & 0.373 & 0.795 & 0.468 & 0.639 & 1.451 & 0.305 & 6.90 \\
\hline
\end{tabular}

Note. $\mathrm{N}=235$;Estimates represent the $\log$ odds of " $\mathrm{DV}=1 "$ vs. " $\mathrm{DV}=0$ " 


\section{Additional Results of Replication}

Table S9. Descriptive table of the participation rates.

\begin{tabular}{|c|c|c|c|c|}
\hline \multirow{2}{*}{ Replication Study } & \multirow{2}{*}{\multicolumn{2}{|c|}{ Experimental Conditions }} & \multicolumn{2}{|c|}{$\begin{array}{c}\text { Combined replication } \\
\text { sample }\end{array}$} \\
\hline & & & $\mathbf{n}$ & $\begin{array}{c}\text { Participation } \\
\text { rate }\end{array}$ \\
\hline \multirow{3}{*}{$\begin{array}{l}\text { Replication of } \\
\text { Experiment } 1 \text { from } \\
\text { Johnson \& Goldstein } \\
(2003)\end{array}$} & \multicolumn{2}{|c|}{ Opt-in default } & 488 & $62.5 \%$ \\
\hline & \multicolumn{2}{|c|}{ Opt-out default } & 476 & $73.5 \%$ \\
\hline & \multicolumn{2}{|c|}{ No-default (no default) } & 482 & $69.7 \%$ \\
\hline \multirow{6}{*}{$\begin{array}{l}\text { Replication of } \\
\text { Experiment } 2 \text { from } \\
\text { Johnson, Bellman \& } \\
\text { Lohse (2002) }\end{array}$} & \multirow{2}{*}{ Opt-in default } & Positive Framing & 324 & $88.6 \%$ \\
\hline & & Negative Framing & 324 & $33.6 \%$ \\
\hline & \multirow{2}{*}{ Opt-out default } & Positive Framing & 321 & $93.1 \%$ \\
\hline & & Negative Framing & 319 & $27.6 \%$ \\
\hline & \multirow{2}{*}{ No-default (no default) } & Positive Framing & 320 & $93.4 \%$ \\
\hline & & Negative Framing & 312 & $25.3 \%$ \\
\hline
\end{tabular}

Note. $\mathrm{N}=1920$; 
Table S10. Descriptive table of the participation rates presented by Sample 1 and Sample 2

\begin{tabular}{|c|c|c|c|c|c|c|}
\hline \multirow[b]{2}{*}{ Replication Study } & \multirow{2}{*}{\multicolumn{2}{|c|}{ Experimental Conditions }} & \multicolumn{2}{|c|}{ Mturk Sample 1} & \multicolumn{2}{|c|}{ Mturk Sample 2} \\
\hline & & & $\mathbf{n}$ & $\begin{array}{c}\text { Participation } \\
\text { rate }\end{array}$ & $\mathbf{n}$ & $\begin{array}{c}\text { Participatio } \\
\text { n rate }\end{array}$ \\
\hline \multirow{3}{*}{$\begin{array}{l}\text { Replication of Experiment } \\
1 \text { from Johnson \& } \\
\text { Goldstein (2003) }\end{array}$} & \multicolumn{2}{|c|}{ Opt-in default } & 161 & $59.0 \%$ & 327 & $64.2 \%$ \\
\hline & \multicolumn{2}{|c|}{ Opt-out default } & 157 & $71.3 \%$ & 320 & $74.6 \%$ \\
\hline & \multicolumn{2}{|c|}{ No-default (no default) } & 162 & $67.3 \%$ & 319 & $70.9 \%$ \\
\hline \multirow{6}{*}{$\begin{array}{l}\text { Replication of Experiment } \\
2 \text { from Johnson, Bellman } \\
\text { \& Lohse (2002) }\end{array}$} & \multirow{2}{*}{ Opt-in default } & Positive Framing & 160 & $84.4 \%$ & 164 & $92.7 \%$ \\
\hline & & Negative Framing & 161 & $30.4 \%$ & 163 & $36.8 \%$ \\
\hline & \multirow{2}{*}{ Opt-out default } & Positive Framing & 162 & $88.9 \%$ & 159 & $97.5 \%$ \\
\hline & & Negative Framing & 159 & $22.6 \%$ & 160 & $32.5 \%$ \\
\hline & \multirow{2}{*}{ No-default (no default) } & Positive Framing & 157 & $91.1 \%$ & 163 & $95.7 \%$ \\
\hline & & Negative Framing & 155 & $26.5 \%$ & 157 & $24.2 \%$ \\
\hline
\end{tabular}

Note. Sample $1(\mathrm{~N})=$ 954; Sample $2(\mathrm{~N})=966$; 
Table S11.

Summary of the replication results: Logistic regression analysis conducted separately for Sample 1 and Sample 2

\begin{tabular}{|c|c|c|c|c|c|c|}
\hline Target & Predictor & Estimate & $S E$ & $\begin{array}{c}Z \\
\text { statistic }\end{array}$ & $p$ & $\begin{array}{l}\text { Odds ratio with } 95 \% \\
\text { C.I. }\end{array}$ \\
\hline \multicolumn{7}{|l|}{ Mturk sample 1} \\
\hline \multirow{2}{*}{$\begin{array}{l}\text { Part } 1 \text { (Johnson \& Goldstein, } \\
\text { 2003) }\end{array}$} & Intercept & 0.36 & 0.16 & 2.27 & 0.023 & $1.44[1.05,1.98]$ \\
\hline & Default: Opt-out - Opt-in & 0.55 & 0.24 & 2.30 & 0.022 & $1.73[1.09,2.77]$ \\
\hline \multirow{5}{*}{$\begin{array}{l}\text { Part } 2 \text { (Johnson, Bellman \& } \\
\text { Lohse, 2002) }\end{array}$} & Intercept & -0.83 & 0.17 & -4.83 & 0.000 & $0.44[0.31,0.61]$ \\
\hline & Framing: Positive - Negative & 2.51 & 0.28 & 9.07 & 0.000 & $12.34[7.17,21.24]$ \\
\hline & Framing $*$ Defaults: & & & & & \\
\hline & (Positive - Negative) $*$ (No-default-Opt-in) & 0.83 & 0.43 & 1.92 & 0.055 & $2.30[0.98,5.39]$ \\
\hline & (Positive - Negative) $*($ Opt-out - Opt-in) & 0.80 & 0.42 & 1.90 & 0.057 & $2.21[0.98,5.03]$ \\
\hline \multicolumn{7}{|l|}{ Mturk sample 2} \\
\hline \multirow{7}{*}{$\begin{array}{l}\text { Part } 2 \text { (Johnson, Bellman \& } \\
\text { Lohse, 2002) }\end{array}$} & Intercept & -0.54 & 0.16 & -3.33 & 0.001 & $0.58[0.42,0.80]$ \\
\hline & Default: No-default - Opt-in & -0.60 & 0.25 & -2.43 & 0.015 & $0.55[0.34,0.89]$ \\
\hline & Default: Opt-out - Opt-in & -0.19 & 0.23 & -0.81 & 0.416 & $0.83[0.52,1.31]$ \\
\hline & Framing: Positive - Negative & 3.08 & 0.34 & 9.03 & $<.001$ & $21.74[11.15,42.42]$ \\
\hline & Framing $*$ Defaults: & & & & & \\
\hline & (Positive - Negative) $*($ No-default- Opt-in) & 1.17 & 0.55 & 2.13 & 0.033 & $3.21[1.10,9.39]$ \\
\hline & (Positive - Negative) $*($ Opt-out-Opt-in) & 1.31 & 0.63 & 2.07 & 0.039 & $3.70[1.07,12.81]$ \\
\hline
\end{tabular}

Note. Estimates represent the odds of dependent variable = "1" vs. "0"; N (Sample 1)= 480; N (Sample 2) = 966; 


\section{Notes on Johnson \& Goldstein (2003) replication:}

In sample 1, participants in the No-Default condition were not more likely to consent to organ donation (67.3\%) than participants the Opt-In condition $(59.0 \%)(b=0.36, p=.124, \mathrm{OR}=1.43,95 \%$ CI $[0.91,2.26])$. In sample 2, participants in the No-

Default condition were more likely to consent to organ donation $(70.9 \%)$ than participants the Opt-In condition $(64.2 \%)(b=0.31, p=$ $.068, \mathrm{OR}=1.36,95 \% \mathrm{CI}[0.98,1.90])$.

\section{Notes on Johnson et al. (2002) replication:}

In sample 1, participants in the No-Default did not consent to receive health-related information (59.0\%) at a higher rate than participants the Opt-In condition $(57.3 \%)(b=-0.20, p=.433, \mathrm{OR}=0.82,95 \%$ CI $[0.50,1.34])$. In sample 2, participants in the NoDefault condition consented to receive health related information (60.6\%) at a lower rate than participants the Opt-In condition $(64.8 \%)(b=-0.60, p=.015, \mathrm{OR}=0.55,95 \% \mathrm{CI}[0.34,0.89])$. 
Table S12.

Johnson et al. 's (2002) replication : Descriptive table of the participation rates split by framing

\begin{tabular}{lccc|cc}
\hline \multirow{2}{*}{ Replication Study } & $\begin{array}{l}\text { Default Experimental } \\
\text { Conditions }\end{array}$ & n & \begin{tabular}{c} 
Positive frame \\
Participation \\
\cline { 3 - 6 }
\end{tabular} & rate & \multicolumn{2}{c}{ Negative frame } \\
\hline Replication of Experiment & Opt-in default & 324 & $88.6 \%$ & 324 & $33.6 \%$ \\
1 from Johnson \& & Opt-out default & 321 & $93.1 \%$ & 319 & $27.6 \%$ \\
Goldstein (2003) & No-default (no default) & 320 & $93.4 \%$ & 312 & $25.3 \%$ \\
\hline
\end{tabular}




\section{Table S13.}

Summary of the Johnson et al. 's (2002) replication results: Logistic regression analysis conducted separately for each frame

\begin{tabular}{|c|c|c|c|c|c|c|}
\hline Target & Predictor & Estimate & $S E$ & $\begin{array}{c}Z \\
\text { statistic }\end{array}$ & $p$ & $\begin{array}{l}\text { Odds ratio with } 95 \% \\
\text { C.I. }\end{array}$ \\
\hline \multicolumn{7}{|l|}{ By Positive Frame } \\
\hline \multirow{2}{*}{$\begin{array}{l}\text { Part } 1 \text { (Johnson \& Goldstein, } \\
\text { 2003) }\end{array}$} & Intercept & 2.13 & 0.38 & 5.58 & $<.001$ & $8.40[3.98,17.74]$ \\
\hline & Default: Opt-out - Opt-in & 0.58 & 0.28 & 2.04 & 0.025 & $1.79[1.03,3.11]$ \\
\hline \multicolumn{7}{|l|}{ By Negative Frame } \\
\hline $\begin{array}{l}\text { Part } 1 \text { (Johnson \& Goldstein, } \\
\text { 2003) }\end{array}$ & Default: Opt-out - Opt-in & -0.29 & 0.17 & -1.66 & 0.096 & $0.75[0.54,1.05]$ \\
\hline
\end{tabular}




\section{Additional Results of Extension hypotheses}

Table S14. Descriptive table for extension hypotheses.

\begin{tabular}{|c|c|c|c|c|}
\hline \multirow[b]{2}{*}{ Extensions } & \multirow{2}{*}{\multicolumn{2}{|c|}{ Experimental Conditions }} & \multicolumn{2}{|c|}{ Mturk Sample 1} \\
\hline & & & $\mathbf{n}$ & $\begin{array}{c}\text { Participation } \\
\text { rate }\end{array}$ \\
\hline \multirow{3}{*}{$\begin{array}{l}\text { Mturk Sample 1: Organ donor study in the } \\
\text { temporary organ-donor condition. }\end{array}$} & \multirow{3}{*}{\multicolumn{2}{|c|}{$\begin{array}{c}\text { Opt-in default } \\
\text { Opt-out default } \\
\text { No-default (no default) }\end{array}$}} & 155 & $63.2 \%$ \\
\hline & & & 161 & $72.7 \%$ \\
\hline & & & 158 & $74.7 \%$ \\
\hline \multirow{6}{*}{$\begin{array}{l}\text { Mturk Sample 2: Organ donor scenario adopted } \\
\text { with both framing and default effects. }\end{array}$} & \multirow{2}{*}{ Opt-in default } & Positive Framing & 164 & $17.7 \%$ \\
\hline & & Negative Framing & 163 & $57.1 \%$ \\
\hline & \multirow{2}{*}{ Opt-out default } & Positive Framing & 159 & $29.6 \%$ \\
\hline & & Negative Framing & 160 & $70.6 \%$ \\
\hline & \multirow{2}{*}{$\begin{array}{l}\text { No-default (no } \\
\text { default) }\end{array}$} & Positive Framing & 163 & $27.6 \%$ \\
\hline & & Negative Framing & 157 & $66.2 \%$ \\
\hline
\end{tabular}

Note. Sample $1(\mathrm{~N})=$ 954; Sample $2(\mathrm{~N})=966$; 


\section{Framework for evaluation of the replications}

Table S15. Criteria for evaluation of replications by LeBel et al. (2018). A classification of relative methodological similarity of a replication study to an original study. "Same" ("different") indicates the design facet in question is the same (different) compared to an original study. IV = independent variable. DV = dependent variable. "Everything controllable" indicates design facets over which a researcher has control. Procedural details involve minor experimental particulars (e.g., task instruction wording, font, font size, etc.).

\begin{tabular}{|c|c|c|c|c|c|}
\hline Target similarity & Highly similar & & & & Highly dissimilar \\
\hline Category & Direct replication & & & & Conceptual replication \\
\hline Design facet & Exact replication & $\begin{array}{l}\text { Very close } \\
\text { replication }\end{array}$ & Close replication & Far replication & $\begin{array}{l}\text { Very far } \\
\text { replication }\end{array}$ \\
\hline Effect/ Hypothesis & Same/similar & Same/similar & Same/similar & Same/similar & Same/similar \\
\hline IV operationalization & Same/similar & Same/similar & Same/similar & Different & Different \\
\hline DV operationalization & Same/similar & Same/similar & Same/similar & Different & Different \\
\hline IV stimuli & Same/similar & Same/similar & Different & Different & \\
\hline DV stimuli & Same/similar & Same/similar & Different & & \\
\hline Procedural details & Same/similar & Different & & & \\
\hline Physical setting & Same/similar & Different & & & \\
\hline Contextual variables & Different & & & & \\
\hline
\end{tabular}


Figure S2. Criteria for evaluation of replications by LeBel et al. (2019). A taxonomy for comparing replication effects to target article original findings.

\section{A Signal Detected in Original Study}

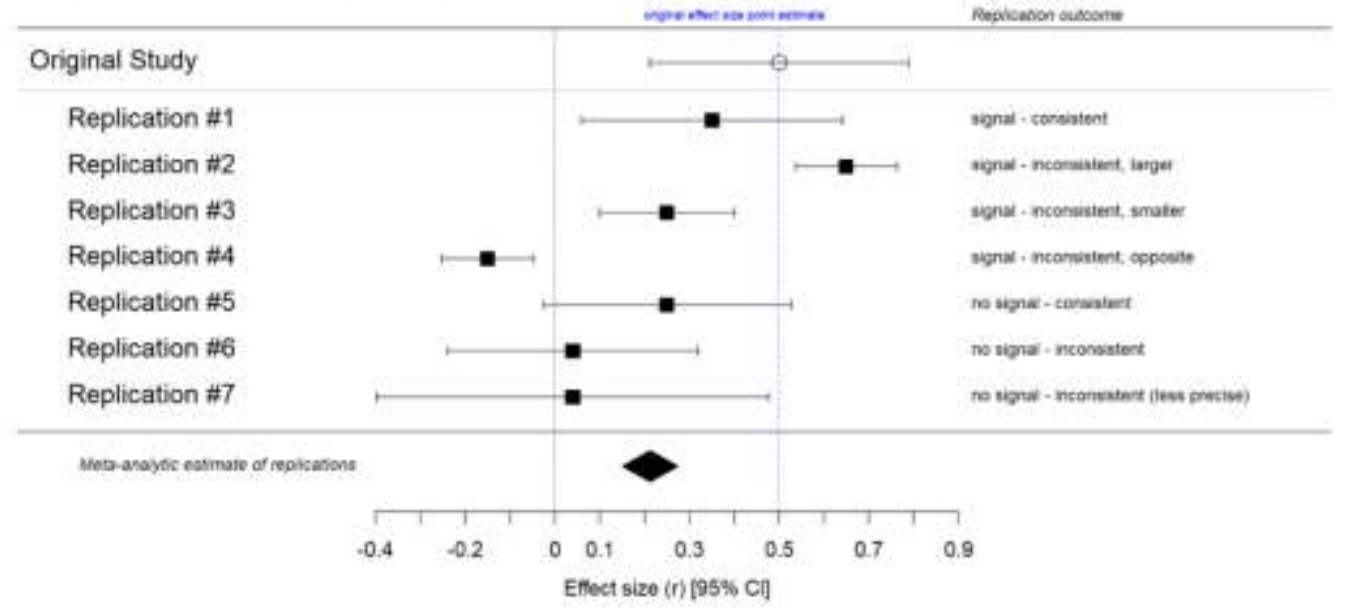

Note: LeBel et al. (2019) suggested a replication evaluation using three factors: (a) whether a signal was detected (i.e., the confidence interval for the replication Effect size (ES) excludes one), (b) consistency of the replication ES with the original study's ES, and (c) precision of the replication's ES estimate (see Figure S\# in the supplementary material). 


\section{References}

Fual, F., Erdfelder, E., Lang, A., \& Buchner, A. (2007). G*Power: A flexible statistical power analysis program for the social, behavioral, and biomedical sciences. Behavior Research Methods, 39(2), 175-191. https://doi.org/10.3758/BF03193146

The jamovi project (2020). jamovi (Version 1.2) [Computer Software]. Retrieved from https://www.jamovi.org

Johnson, E. J., Bellman, S., \& Lohse, G. L. (2002). Defaults, framing and privacy: Why opting in-opting out. Marketing Letters, 13(1), 5-15.

Johnson, E. J., \& Goldstein, D. (2003). Do defaults save lives? Science, 302, 1338-1339. 